\title{
ASPECTOS PROCESALES DE LAS ACCIONES DE DAÑOS DERIVADOS DE INFRACCIONES DE LAS NORMAS SOBRE DEFENSA DE LA COMPETENCIA: APUNTES A LA LUZ DE LA DIRECTIVA 2014/104 Y DE LA PROPUESTA DE LEY DE TRANSPOSICIÓN
}

\author{
PROCEDURAL ISSUES OF ANTITRUST DAMAGES CLAIMS: \\ SOME NOTES IN THE LIGHT OF THE 2014 DIRECTIVE \\ AND THE PROPOSAL FOR ITS TRANSPOSITION INTO \\ THE SPANISH LEGAL SYSTEM
}

\author{
FERnANDo Gascón InCHAUSTI \\ Catedrático de Derecho Procesal \\ Universidad Complutense de Madrid
}

Recibido: 15.01.2017 / Aceptado: 24.01.2017

DOI: https://doi.org/10.20318/cdt.2017.3616

\begin{abstract}
Resumen: Este trabajo se centra en algunos aspectos procesales que suscita el ejercicio de acciones en reclamación de daños derivados de infracciones al Derecho de la competencia, analizando el modo en que los abordan la Directiva 2014/104/UE y la propuesta de ley de 2015 para su transposición al ordenamiento español. En primer término se tratan determinadas cuestiones relativas a la jurisdicción y la competencia. Se constata seguidamente el reducido margen de maniobra en esta materia que ofrece el vigente sistema legal de acciones colectivas. La atención se dirige, después, a las cuestiones de índole probatoria, con especial énfasis en el sistema de acceso a las fuentes de prueba en poder de la parte contraria o de terceros (especialmente las autoridades nacionales de competencia). Por último, se analizan las herramientas que permiten coordinar el proceso civil con otros procesos civiles y también, de forma especial, con el procedimiento sancionador tramitado por la autoridad de competencia.

Palabras clave: acciones de daños por infracción de normas de competencia, Directiva 2014/104/ UE, aplicación privada del Derecho de la competencia, acceso a fuentes de prueba, eficacia vinculante de las resoluciones de autoridades nacionales de competencia, armonización legislativa, acciones colectivas, prueba del daño, amicus curiae.
\end{abstract}

\begin{abstract}
This paper focuses on some procedural issues associated to antitrust damages claims and analyses the way they are addressed by the Directive 2014/104/EU and the 2015 proposed draft act to implement it in the Spanish legal system. After considering some jurisdiction issues and the (reduced) margin left to collective redress mechanisms, the author focuses on two specific issues: on the one hand, evidential matters, with specific consideration to the means to get access to information and evidence in the possession of the counterparty or of a non-party; on the other hand, the need to deal with the interaction of judicial proceedings, also with public enforcement proceedings led by competition authorities.

Keywords: antitrust damages claims, Directive 2014/104/EU, private enforcement of competition law, access to information and evidence, binding effect of national competition authorities' decisions, legal harmonization, collective claims, proof of damage, amicus curiae.
\end{abstract}

*Este trabajo se enmarca dentro del Proyecto de Investigación "La armonización del proceso civil en la Unión Europea" (DER2015-64756-P), financiado por el MINECO. 
Sumario: I. Introducción. II. Cuestiones en relación con la determinación del tribunal competente. III. Cuestiones en relación con la legitimación activa. 1. La posibilidad de ejercicio de acciones colectivas. 2. La acumulación de pretensiones por parte de empresarios perjudicados y la transmisión onerosa del crédito indemnizatorio. IV. Problemas en relación con la determinación de los hechos y con la prueba. 1. Facilitaciones probatorias. A) Presunciones legales. B) La prueba de la cuantía de los daños. a) La estimación del importe de los daños. b) El asesoramiento de las autoridades nacionales de competencia. C) La determinación de la ilicitud de la conducta en acciones consecutivas. 2. Acceso a fuentes de prueba en poder del contrario y de terceros. A) La propuesta de incorporación de las reglas de la Directiva a través de la introducción generalizada de medidas de acceso a fuentes de prueba en el proceso civil español. B) Las reglas especiales sobre acceso a fuentes de prueba respecto de acciones de daños en materia de defensa de la competencia. a) Sistema general. b) Reglas especiales en relación con las pruebas contenidas en un expediente de una autoridad nacional de competencia. V. La coordinación de procesos judiciales entre sí y con procedimientos sancionadores a cargo de autoridades nacionales de competencia. 1. Coordinación entre proceso judicial y expediente administrativo sancionador. 2. Coordinación entre procesos judiciales.

\section{Introducción}

1. La aplicación privada del Derecho de la competencia no es a estas alturas ninguna novedad. Incluso cuando el marco normativo no era singularmente explícito en este punto, ni a nivel europeo ni a nivel nacional, el Tribunal de Justicia de la UE dejó bien claro en los asuntos Courage y Manfredi que resulta siempre posible que quien se ha visto perjudicado por conductas contrarias a las normas sobre competencia reclame una indemnización de los daños que aquéllas le hayan irrogado. ${ }^{1}$ Se trata, de hecho, de un elemento que el propio TJUE consideró clave para dotar de plena eficacia al sistema general de tutela de la competencia, que se vería en entredicho "si no existiera la posibilidad de que cualquier persona solicite la reparación del perjuicio que le haya irrogado un contrato o un comportamiento susceptible de restringir o de falsear el juego de la competencia". ${ }^{2}$

2. En defecto de pactos y acuerdos, una parte sustancial del private enforcement del Derecho de la competencia se ha de materializar a través de procesos civiles en que se ejerciten acciones de indemnización de los daños y perjuicios ocasionados por conductas susceptibles de calificarse -lato sen$s u$ - como abusos de posición dominante o como pactos colusorios (cárteles). ${ }^{3}$ De hecho, durante mucho tiempo, tanto nuestro legislador interno como el legislador europeo han asumido que habrá de tratarse de procesos civiles ordinarios -en el sentido coloquial del término, equivalente a "normales y corrientes"-, sin singulares especialidades en atención a la materia sobre la que versan o a las dificultades intrínsecas que la práctica haya puesto de manifiesto (o que pudieran vaticinarse). ${ }^{4}$

3. En nuestro ordenamiento el ejercicio de estas acciones ha sido siempre posible: el artículo 6 de la Ley de 1963 y el artículo 13.2 de la Ley de 1989, sin embargo, establecían un requisito procesal singular, consistente en que ya hubiera concluido en firme el procedimiento sancionador en que se hubiera declarado la comisión de una práctica prohibida. ${ }^{5} \mathrm{Su}$ ámbito, por tanto, se hallaba restringido a las

${ }^{1}$ STJUE de 20 de septiembre de 2001, Courage y Crehan, C-453/99, Rec. 2001, p. I-06297, especialmente en los apartados 24 y siguientes); STJUE de 13 de julio de 2006, Manfredi, asuntos acumulados C-295/04 a C-298/04, Rec. 2006, p. I-06619, (cfr. en especial los apartados 39, 58 a 64 y 95). Debe tenerse en cuenta, no obstante, que con anterioridad a estas resoluciones, el TJUE ya había reconocido eficacia horizontal a las normas sobre defensa de la competencia en varias ocasiones (cfr., entre otras, STJUE de 30 de enero de 1974, BRT 1, 127/73, Rec. 1974, p. 00035, apartado 16; STJUE de 18 de marzo de 1997, Guérin automobiles/Comisión, C-282/95 P, Rec. 1997, p. I-01503, apartado 39).

2 STJUE de 20 de septiembre de 2001, Courage y Crehan, C-453/99, Rec. 2001, p. I-06297, apartado 26.

3 Aunque no exclusivamente: también son posibles acciones de nulidad contractual al amparo de lo establecido en los artículos 101.2 TFUE y 1.2 LDC.

${ }^{4}$ La Sentencia Manfredi reconoció que, ante la inexistencia de normativa comunitaria en esta materia, correspondía a los ordenamientos nacionales definir el régimen procesal de los instrumentos para dar aplicación a la eficacia directa de las normas europeas de competencia (cfr. apartados 62 y 64).

5 En concreto, el artículo 6 de la Ley 110/1963, de 20 de julio, de represión de prácticas restrictivas de la competencia 
reclamaciones y a las acciones de tipo consecutivo o follow-on. Esta exigencia desapareció con la vigente Ley 15/2007, de 3 de julio, de Defensa de la Competencia (LDC, en lo sucesivo). Es cierto que suprimiendo esta limitación se facilitó la aplicación privada del Derecho de la competencia, al abrir las puertas a acciones de carácter independiente o stand alone; sin embargo, salvando este dato, que legalmente se tradujo realmente en una omisión, la atención expresa que recibieron las acciones de daños por parte del legislador fue mínima: ${ }^{6}$ de hecho, lo único que se hizo en este punto fue modificar el artículo 86 ter 2 f) de la LOPJ -para atribuir competencia objetiva a los Juzgados de lo Mercantil también para la aplicación de lo dispuesto en los nuevos artículos 1 y 2 - y dar efectividad a algunas exigencias del Reglamento 1/2003, destinadas a permitir la intervención de las autoridades de defensa de la competencia en este tipo de procesos y hacer posible una mínima coordinación entre los procesos judiciales civiles y los procedimientos administrativos sancionadores tramitados por las autoridades de defensa de la competencia. ${ }^{7}$ Pero lo cierto es que no se incorporaron entonces especialidades sustantivas o procesales realmente significativas.

4. Abordar la litigación privada en materia de Derecho de la competencia con las reglas comunes del proceso civil, sin embargo, no parece haber conducido a resultados destacables en la práctica: no han sido muchos los litigios -al menos en España, aunque se aprecie un claro incremento ${ }^{8}{ }^{8}$ siguen siendo numerosas las dificultades reales que, sin duda, pueden tener alcance disuasorio para potenciales demandantes. ${ }^{9}$

5. La Unión Europea ha sido consciente de esto desde hace ya bastante tiempo; al menos, desde 2005, cuando lanzó el Libro Verde sobre esta materia ${ }^{10}$, que desembocó, a su vez en el Libro Blanco de $2008^{11}$ y en la Propuesta de Directiva de 2013. ${ }^{12}$ Las autoridades europeas constataron desde el principio que era necesario dotar de un régimen jurídico especial a las acciones de daños por infracciones a las reglas sobre competencia, tanto en el plano sustantivo, como en el procesal. ${ }^{13}$ En lo sustantivo, porque la aplicación de las reglas comunes sobre responsabilidad civil extracontractual puede ser insuficiente para abordar adecuadamente problemas como los que generan la repercusión de sobrecostes, la responsabilidad solidaria de los partícipes de un cártel o el plazo de prescripción. Y en lo procesal, porque se trata por definición de procesos que se integran en un contexto de "litigación compleja" y que, en todo caso,

establecía, bajo la rúbrica "Acción de resarcimiento", lo siguiente: "Los perjudicados por las prácticas restrictivas declaradas prohibidas por el Tribunal de Defensa de la Competencia podrán ejercitar acción de resarcimiento de daños y perjuicios ante la jurisdicción civil ordinaria en plazo no superior a un año, a contar del día en que sea firme la declaración del Tribunal." Y, por su parte, el artículo 13.2 de la Ley 16/1989, de 17 de julio, de Defensa de la competencia, lo precisaba algo más: "La acción de resarcimiento de daños y perjuicios, fundada en la ilicitud de los actos prohibidos por esta Ley, podrá ejercitarse por los que se consideren perjudicados, una vez firme la declaración en vía administrativa y, en su caso, jurisdiccional. El régimen sustantivo y procesal de la acción de resarcimiento de daños y perjuicios es el previsto en las leyes civiles."

${ }^{6}$ Así lo puso de manifiesto con agudeza I. Dízz-Picazo Giménez, "Sobre algunas dificultades para la llamada "aplicación privada" de las normas de competencia en España", 1989-2007 Una reflexión sobre la política de defensa de la competencia - Libro marrón del Círculo de Empresarios, Madrid, 2008, pp. 53-74, p. 59: “(...) al "private enforcement” del Derecho de la competencia sólo se dedican el párrafo antepenúltimo y penúltimo de la exposición de motivos y las disposiciones adicionales primera y segunda".

7 A través de la introducción en la LEC de un nuevo artículo 15 bis y de la adición de nuevos párrafos o apartados en los artículos 212.3, 404, 434.3 y 461.5 .

${ }^{8}$ Cfr. F. Marcos Fernández, "La aplicación privada del Derecho de defensa de la competencia por los tribunales españoles", ICE-Información Comercial Española, no 876, enero-febrero 2014, pp. 91-104, que contabiliza 323 casos (desde la aprobación de la Ley 110/1963 hasta mediados de 2012).

9 Cfr., nuevamente, I. DíEz-Picazo Giménez, “Sobre algunas dificultades...”, cit., pp. 60 y ss., que las condensa en las siguientes: procedimientos simultáneos, ineficacia de las acciones colectivas, clemencia y responsabilidad por daños, la prueba del ilícito y la prueba del daño.

10 Libro Verde - Reparación de daños y perjuicios por incumplimiento de las normas comunitarias de defensa de la competencia, de 19 de diciembre de 2005 [SEC(2005) 1732; Documento COM/2005/0672 final].

11 Libro Blanco - Acciones de daños y perjuicios por incumplimiento de las normas comunitarias de defensa de la competencia, de 2 de abril de 2008 [Documento COM(2008) 165 final].

12 Propuesta de Directiva de 11 de junio de 2013 [COM(2013) 404 final].

13 De hecho, la propia Unión Europea, como es bien sabido, interpuso una demanda civil ante un tribunal belga en reclamación de los daños padecidos como consecuencia del cártel de los ascensores y escaleras mecánicas (y que desembocó, ante el planteamiento de cuestión prejudicial, en la STJUE de 6 de noviembre de 2012, C-199/11, Otis). 
presentan singulares dificultades en el terreno de la determinación de los hechos y de la coordinación con procedimientos administrativos y/o judiciales conexos.

6. El esfuerzo de las instituciones europeas por afrontar ambas cuestiones acabó cristalizando, como es bien sabido, en la Directiva 2014/104/UE del Parlamento Europeo y del Consejo, de 26 de noviembre de 2014, relativa a determinadas normas por las que se rigen las acciones por daños en virtud del Derecho nacional, por infracciones del Derecho de la competencia de los Estados miembros y de la Unión Europea ${ }^{14}$. El propósito de la Directiva es dar cobertura a varias de las necesidades de regulación especial que, tanto en lo sustantivo como en lo procesal, plantea un ejercicio eficaz de las acciones de daños en este ámbito; con ello, se aspira también a dar cumplimiento al principio europeo de máxima eficacia de la normativa de defensa de la competencia, eficacia a la que puede contribuir claramente un ejercicio efectivo de estas acciones.

7. La incorporación de la Directiva a los ordenamientos nacionales debería haberse realizado a más tardar el 27 de diciembre de 2016, aunque también en este caso parece que el incumplimiento será la regla y, desde luego, lo será en el caso de nuestro país, aunque no tendría por qué haber sido necesariamente así. ${ }^{15}$ En efecto, en febrero de 2015 se constituyó una sección especial, dentro de la Comisión General de Codificación, para la trasposición de la Directiva, ${ }^{16}$ que presentó en noviembre de ese mismo año una propuesta de ley a tal fin -y a la que se dio difusión el 15 de enero de 2016-. ${ }^{17}$ El prolongado periodo de parálisis política y parlamentaria experimentado a partir de ese momento ha determinado la imposibilidad de aprobar la norma correspondiente y, de hecho, en el momento de escribir estas páginas, ni siquiera puede sostenerse con seguridad si una futura iniciativa parlamentaria en este ámbito tomará como punto de partida el texto de la propuesta de 2015. Sea como fuere, el objetivo de estas páginas

14 DO L 349, de 5 de diciembre de 2014, pp. 1-19. La doctrina generada en torno a los primeros proyectos y a la versión definitiva de la Directiva comienza a ser más que destacable. En nuestro país, entre otros , cfr. J. Alfaro ÁguILA-REAL, "Contra la armonización positiva: la Propuesta de la Comisión para reforzar el private enforcement del Derecho de la Competencia", InDret 3/2009; H. BRokelmanN, "La Directiva de daños y su transposición en España”, Revista General de Derecho Europeo 37 (2015); P. CAllol / M. Yuste, "La directiva comunitaria sobre reclamación de daños y perjuicios derivados de infracciones del Derecho de la competencia. Principales novedades y potencial incidencia en el ordenamiento jurídico español”, en M.A. ReCUERDA GIRELA (coord.), Problemas prácticos y actualidad del Derecho de la Competencia. Anuario 2015, Civitas, Cizur Menor, 2015, pp. $297-$ 315; A.L. Calvo Caravaca / J. Suderow, "El efecto vinculante de las resoluciones de las autoridades nacionales de competencia en la aplicación privada del Derecho antitrust", Cuadernos de Derecho Transnacional (Octubre 2015), Vol. 7, № 2, pp. 114-157; A. Font i RiBAs / B. VILÀ Costa (dirs.), La indemnización por infracción de normas comunitarias de la competencia, Marcial Pons, Madrid-Barcelona-Buenos Aires-Sao Paulo, 2012; C. Herrero SuÁrez, "La transposición de la directiva de daños antitrust. Reflexiones a raíz de la publicación de la propuesta de ley de transposición de la directiva", Cuadernos de Derecho Transnacional (Marzo 2016), Vol. 8, № 1, pp. 150-183; J. JiméNez-LAiglesia / J. MAsía TeJEDOR, "Examen de cuestiones de naturaleza práctica relativas a la aplicación privada del Derecho de la Competencia en España", Gaceta jurídica de la Unión Europea y de la competencia, No 30, 2012, pp. 26-39; D. Ordoñez Solís, "La Directiva 2014/104/UE, la aplicación privada del derecho de la competencia y el contexto jurisprudencial de su transposición en España”, ElDerecho.com (1 de enero de 2015); S. Oromí VALL-LLOBERA, "El ejercicio de acciones de responsabilidad civil por los perjudicados en materia de derecho de la competencia. Aspectos procesales", Revista Vasca de Derecho Procesal y Arbitraje, XXVIII, 2016-1, pp. 101-115; I. OrTIZ BAQUero, La aplicación privada del Derecho de la competencia. Los efectos civiles de la infracción de las normas de libre competencia, La Ley, Madrid, 2011; M. Pedraz Calvo / D. Ordónez Solís (coords.), El Derecho Europeo de la Competencia y su aplicación en España. Liber amicorum en Homenaje a Santiago Martínez Lage, Wolters Kluwer, Madrid, 2014; J.I. RuIz Peris (dir.), La compensación de los daños por infracción de las normas de competencia tras la Directiva 2014/104/UE. Directiva y propuesta de transposición, Aranzadi, Cizur Menor, 2016; I. SANCHO GARGallo, "Ejercicio privado de las acciones basadas en el derecho comunitario y nacional de la competencia", InDret 1/2009; M.V. TORRE SUSTAETA, La aplicación del Derecho de la competencia en Europa. Intereses en juego y vías de tutela, Aranzadi, Cizur Menor, 2014; Id., Daños y perjuicios por infracción de las normas de Derecho de la competencia. La tutela procesal del Derecho de la competencia en el plano nacional español, Aranzadi, Cizur Menor, 2016.

15 A 23 de enero de 2017, desde luego, sólo habían aprobado la normativa de trasposición necesaria Dinamarca, Eslovaquia, Finlandia, Hungría, Letonia, Luxemburgo y Suecia, según la información facilitada en esa fecha por la propia Comisión en la web http://ec.europa.eu/competition/antitrust/actionsdamages/directive_en.html.

16 Orden de 16 de febrero de 2015, por la que se constituye una sección especial para la trasposición de la directiva 2014/104/UE, sobre la regulación de las acciones por daños en virtud de derecho nacional y por infracciones del derecho de la competencia (accesible en la página web del Ministerio de Justicia, http://www.mjusticia.gob.es/).

17 Propuesta de Ley de la Sección Especial para la Trasposición de la Directiva 2014/104/UE, del Parlamento Europeo y del Consejo, de 26 de noviembre de 2014. (también accesible en la página web del Ministerio de Justicia, http://www.mjusticia. gob.es/) 
consiste en identificar los principales problemas de índole procesal que suscita un ejercicio eficaz de las acciones de daños en materia de Derecho de la competencia y en verificar hasta qué punto la Directiva -y la propuesta de ley de 2015- aportan soluciones realmente útiles.

\section{Cuestiones en relación con la determinación del tribunal competente}

8. Las acciones por daños derivados de infracciones a las normas sobre defensa de la competencia revisten una complejidad suficiente como para justificar que su enjuiciamiento pueda ser atribuido a tribunales especializados. Aunque se trata de una cuestión en la que la Directiva no entra -no podría, dada la ausencia de competencia de las instituciones europeas para incidir en la organización jurisdiccional interna de los Estados miembros-, lo cierto es que en nuestro ordenamiento este postulado se ha asumido sin dificultad y se ha traducido en la atribución de la competencia objetiva para conocer de estos procesos a los Juzgados de lo Mercantil, a través del artículo 86 ter 2 f) LOPJ y de la D.A. $1^{\text {a }}$ LDC. ${ }^{18}$ En efecto, el primero de ellos encomienda a estos tribunales la competencia para conocer de los "procedimientos de aplicación de los artículos 81 y 82 del Tratado constitutivo de la Comunidad Europea y su derecho derivado, así como los procedimientos de aplicación de los artículos que determine la Ley de Defensa de la Competencia"19; y la segunda, por su parte, señala que "De acuerdo con lo dispuesto en el artículo 86 ter 2. letra f de la Ley Orgánica 6/1985, del Poder Judicial, los Juzgados de lo Mercantil conocerán de cuantas cuestiones sean de la competencia del orden jurisdiccional civil respecto de los procedimientos de aplicación de los artículos 1 y 2 de la presente Ley". ${ }^{20}$

9. Siendo muy rigoristas, cabría cuestionar si las acciones de daños tienen su fundamento jurídico en las normas generales sobre responsabilidad civil extracontractual del Código civil y no, de forma directa, en la LDC o en el TFUE: semejante visión podría usarse, tal vez, para justificar que los procesos para el ejercicio de este tipo de acciones no se hallan cubiertos por el tenor literal del artículo 86 ter 2 f) LOPJ, de modo que su enjuiciamiento debería corresponder a los Juzgados de Primera Instancia, especialmente en las demandas de tipo follow-on, en las que el tribunal del orden civil no tiene por qué pronunciarse acerca de la existencia de una infracción a la normativa de defensa de la competencia. ${ }^{21}$ Aunque la duda parece haberse suscitado en alguna ocasión en el foro ${ }^{22}$ se trata a mi entender de una interpretación incorrecta. De lege lata, porque privaría virtualmente de sentido al precepto: ¿qué otras

18 También I. Sancho Gargallo, “Ejercicio privado...,", cit., pp. 19-20; L.CAballol Angelats, “Aspectos procesales de la reclamación judicial del resarcimiento de daños y perjuicios causados por infracción de normas comunitarias de la competencia”, en A. Font i Ribas / B. Vilà Costa (dirs.), La indemnización por infracción de normas comunitarias de la competencia, cit., pp. 11-43, p. 17; E. Olmedo Peralta, "La reclamación de daños sufridos por los consumidores como consecuencia de un cartel (private enforcement): follow-on damages vs. stand alone actions", en L.M. Miranda SERRAno (dir.), J. Pagador López / M. Pino Abad (coords.), La protección de los consumidores en tiempos de cambio, Iustel, Madrid, 2015, pp. 171-187, p. 172; y V. Torre Sustaeta, Daños y perjuicios..., cit., pp. 58-59.

19 Es importante subrayar que la inclusión de esta materia en el ámbito competencial de los Juzgados de lo Mercantil se estableció desde el inicio mismo de la creación de estos órganos jurisdiccionales. La versión inicial del precepto, introducida por el artículo 2.7 de la Ley Orgánica 8/2003, de 9 de julio, para la Reforma Concursal (para adaptar la LOPJ a la Ley Concursal) se limitaba a atribuir competencia a los Juzgados de lo Mercantil para conocer "De los procedimientos de aplicación de los artículos 81 y 82 del Tratado de la Comunidad Europea y de su derecho derivado". La versión vigente se introdujo, es cierto, con ocasión de la aprobación de la LDC, pero a través de un texto normativo un tanto insólito, la D.F. 1 ${ }^{\text {a }}$ de la Ley Orgánica 13/2007, de 19 de noviembre, para la persecución extraterritorial del tráfico ilegal o la inmigración clandestina de personas.

20 En cualquier caso, resulta llamativo que, a pesar del tiempo transcurrido, y de las numerosas reformas experimentadas por la LOPJ desde la entrada en vigor del Tratado de Funcionamiento de la Unión Europea, el precepto siga haciendo referencia a los ya derogados artículos 81 y 82 TCE, en vez de a los vigentes artículos 101 y 102 TFUE; por desgracia, el legislador nos tiene acostumbrados a desatenciones de este tipo.

${ }^{21}$ Cfr. A. Martínez Sánchez / J. Rodríguez Ordóñez, "La aplicación del Derecho de la competencia por el juez civil español: de unos inicios dubitativos a ¿un futuro prometedor?”, en M. Pedraz Calvo / D. OrdóÑez Solís (dirs.), El Derecho Europeo de la Competencia y su aplicación en España, cit., pp. 413-418.

${ }^{22}$ Es cierto que los asuntos que desembocaron en las dos sentencias dictadas hasta la fecha por la Sala $1^{\mathrm{a}}$ del Tribunal Supremo (SSTS de 7 de noviembre de 2013 y de 9 de enero de 2015) comenzaron ante Juzgados de Primera Instancia; pero la interposición de la demanda fue anterior a la entrada en vigor de la LDC de 2007 y a la reforma del artículo 86 ter 2 f) LOPJ. 
acciones -si no son éstas- cabe imaginar que se ejerciten ante tribunales del orden civil en aplicación de la normativa sobre defensa de la competencia? Pensar que el legislador no ha querido incluirlas, o que sólo pensaba en acciones stand alone y/o que sólo pensaba en acciones de nulidad de contratos por infracción de lo dispuesto en las normas en cuestión es ilógico, máxime cuando el precepto se reformó en 2007, precisamente con ocasión de la aprobación de la LDC que abría la puerta al ejercicio directo, no consecutivo, de este tipo de acciones - equiparándolas, pues-. De cara al futuro, la atribución de esta clase de pretensiones al ámbito de especialización de los Juzgados de lo Mercantil será aún más indudable si, como se hace en la propuesta de 2015, se incluyen en el texto de la LDC las especialidades sustantivas introducidas por la Directiva.

10. ¿Sería deseable una mayor especialización, más allá de la atribución de estos litigios a los Juzgados de lo Mercantil? Cabría pensar, por ejemplo, en seguir el modelo de la Ley de Patentes ${ }^{23}$ como forma de reducir aún más el círculo de posibles juzgadores -que, en consecuencia, podrían estar aún más especializados-, de modo que el enjuiciamiento de estos asuntos correspondiera a los Juzgados de lo Mercantil de la ciudad sede del Tribunal Superior de Justicia de la Comunidad Autónoma: si el legislador optara por este mecanismo, podrían acabar siendo, a lo sumo, 17 los Juzgados de lo Mercantil que conocerían de estos procesos; no parece, sin embargo, que esté en preparación modificación legislativa alguna en este sentido. Una opción más sencilla, que no requiere reforma legal, consiste en servirse a tal fin de las normas de reparto entre Juzgados de lo Mercantil, en las provincias donde haya varios: así parece estar sucediendo, de hecho. Conviene advertir, no obstante, que la concentración de la competencia para el enjuiciamiento de procesos de cuantía potencialmente muy elevada y de consecuencias económicas relevantes en unos pocos juzgadores también presenta inconvenientes, de índole más sociológica o humana que jurídica, pero que no deben desdeñarse.

11. En un plano diverso, el de los criterios de atribución de competencia internacional, debe contarse en primer término con la regla general, que es el fuero del domicilio del demandado (art. 4 RB I bis; art. 22 ter LOPJ). En caso de que sean varios los demandados -situación imaginable con facilidad en supuestos de daños derivados de cártel, especialmente si las empresas implicadas tienen sus respectivas sedes en Estados diferentes-, podrá el demandante interponer su demanda ante los tribunales del Estado donde esté domiciliado cualquiera de ellos, lo que le permitirá, claro está, optar por aquél que le resulte a priori más favorable. Se abre la puerta con ello a un forum shopping que no es fácil evitar y que puede, de hecho, dar lugar a situaciones delicadas, como la que le fue suscitada recientemente al TJUE en el asunto CDC Hydrogen Peroxide, ${ }^{24}$ en que la demanda se interpuso ante tribunales alemanes por estar domiciliada en ese Estado uno de las varias empresas cartelizadas demandadas, aunque con posterioridad, una vez producida la perpetuatio iurisdictionis, la actora renunció a su acción frente a esa entidad (pero dejando sujetas a las demás a la jurisdicción de los tribunales alemanes).

12. Ahora bien, por razón de la materia, en el plano internacional es posible también la aplicación de un fuero especial, el del lugar de producción del hecho dañoso [art. 7.2 RB I bis; art. 22 quinquies b) LOPJ]. La aplicación de este fuero especial al ámbito de las acciones de daños en materia de competencia también se ha suscitado en el asunto CDC Hydrogen Peroxide. ${ }^{25}$ El TJUE parte de la premisa de que estas acciones son acciones por responsabilidad civil extracontractual (materia delictual o cuasidelictual, en la terminología común europea) y, por ello, al amparo del artículo 5.3 RB I (ahora, 7.2 RB I bis), serán competentes los tribunales del lugar donde se haya producido o pueda producirse el hecho dañoso. Esta

23 En concreto, el artículo 118.2 de la Ley 24/2015, de 24 de julio, de Patentes (en vigor a partir del 1 de abril de 2017), directamente inspirado en el artículo 125.2 de la Ley 11/1986, de 20 de marzo, de Patentes.

${ }^{24}$ STJUE de 21 de mayo de 2015, Cartel Damage Claims (CDC) Hydrogen Peroxide SA., asunto C-352/13.

25 Cfr. J. Suderow, "Acciones derivadas de ilícitos antitrust: el foro especial de la obligación extracontractual después de la sentencia CDC Hydrogen Peroxide”, Cuadernos de Derecho Transnacional (Octubre 2016), Vol. 8, № 2, pp. 306-329; C. Oró Martínez, "Reglamento Bruselas I y acciones indemnizatorias derivadas de un cártel: cuestiones de competencia judicial internacional", La Ley Unión Europea, número 30, 2015; M. PenAdÉs Fons, "Reclamaciones de daños transfronterizas y competencia internacional", en J.I. RUIz PerIs (dir.), La compensación de los daños por infracción de las normas de competencia tras la Directiva 2014/104/UE, cit., pp. 451-465. 
referencia, como ha reiterado el TJUE, comprende tanto el lugar de producción del hecho causal como el lugar de producción del daño ${ }^{26}$. Cuando se trata de daños derivados de los sobrecostes causados por la existencia de un cártel, el TJUE ha precisado lo siguiente: (i) en cuanto al lugar del hecho causal, puede tratarse del lugar de constitución del cártel (si se $\operatorname{conoce}^{27}$ ) o el lugar en que se haya concluido un arreglo (de entre los varios arreglos colusorios celebrados para conformar el cártel) "que por sí solo sea el hecho causal del perjuicio supuestamente sufrido por un comprador"28; (ii) en cuanto al lugar de materialización del perjuicio, debe de ordinario identificarse con el domicilio de la víctima.

13. Otra cuestión, que también se puede proyectar en el plano puramente interno, es la que suscita la eficacia de las cláusulas de sumisión expresa o de arbitraje que estén incluidas en los contratos -se puede pensar, sobre todo, en contratos de suministro- entre la empresa demandada -cabe pensar, nuevamente, en una empresa que sea partícipe del cártel- y el comprador directo, perjudicado por la conducta anticompetitiva. En general, se trata de cláusulas amplias y comprensivas de todas las controversias asociadas al contrato en el que se insertan: ¿significa esto, en defecto de previsión expresa, que el pacto de sumisión o de arbitraje también cubre el proceso para reclamación de indemnización por daños derivados de la infracción a las normas de competencia? El problema también lo abordó el STJUE en el asunto CDC Hydrogen Peroxide, de forma más que razonable: a juicio del Tribunal, un pacto de sumisión expresa (o de sumisión a arbitraje, podría añadirse) sólo puede ser eficaz para una acción de daños si la contempla de forma expresa. Ahora bien, en el supuesto ordinario de una cláusula estándar incluida en un contrato de compraventa, suministro o servicio, no puede colegirse que una controversia de este tipo haya sido contemplada por las partes en el momento de su suscripción, de modo que no puede considerarse como una controversia cubierta por la cláusula. ${ }^{29}$

\section{Cuestiones en relación con la legitimación activa}

14. La legitimación activa para el ejercicio de este tipo de acciones de daños, por pura lógica, corresponde a quienes se hayan visto perjudicados por la conducta anticompetitiva. Aunque son posibles categorizaciones muy diversas en este punto, interesa ahora distinguir dos grandes grupos de potenciales demandantes, en tanto que perjudicados. De un lado, se hallan los consumidores de los bienes o los usuarios de los servicios, cuyo perjuicio ha de cifrarse en el mayor precio pagado por aquéllos debido al abuso de posición dominante o a la práctica colusoria. De otro, por supuesto, están los profesionales o empresarios que hayan adquirido los bienes o servicios para incorporarlos a su actividad productiva o comercial, también perjudicados por la conducta anticompetitiva, siempre que no hayan repercutido íntegramente el sobrecoste a terceros. En relación con ambos grupos pueden plantearse cuestiones diversas.

\section{La posibilidad de ejercicio de acciones colectivas}

15. Si los perjudicados son consumidores, es muy difícil imaginar el ejercicio de acciones individuales para reclamar el sobrecoste asociado a prácticas anticompetitivas en el precio de productos

26 Cfr. STJUE CDC Hydrogen Peroxide, apartado 38 "la expresión «lugar donde se hubiere producido o pudiere producirse el hecho dañoso», que figura en el artículo 5, punto 3, del Reglamento n ${ }^{\circ} 44 / 2001$, se refiere al mismo tiempo al lugar donde se ha producido el daño y al lugar del hecho causal que originó ese daño, de modo que la acción contra el demandado puede ejercitarse a elección del demandante ante los tribunales de cualquiera de esos dos lugares (sentencias Melzer, C228/11, EU:C:2013:305, apartado 25, y Kolassa, C375/13, EU:C:2015:37 apartado 45).”

27 Cfr. STJUE CDC Hydrogen Peroxide, apartado 44.

28 Cfr. STJUE CDC Hydrogen Peroxide, apartado 50.

29 Cfr. STJUE CDC Hydrogen Peroxide, apartado 69: “(...) una cláusula que se refiere en abstracto a las controversias que surjan en las relaciones contractuales no abarca una controversia acerca de la responsabilidad delictual en la que hubiera incurrido supuestamente una parte contratante a causa de su conducta en el ámbito de un cártel ilícito.”. Y también apartado 70: “(...) En efecto, toda vez que tal litigio no era razonablemente previsible para la empresa perjudicada cuando dio su consentimiento a esa cláusula, pues desconocía en ese momento el cártel ilícito en el que participaba la otra parte contratante, no se puede considerar que ese litigio tenga su origen en las relaciones contractuales. Por tanto, la referida cláusula no excluiría válidamente la competencia del tribunal (...)". 
cotidianos como la leche, el azúcar o el cartón, entre otros muchos posibles. A tal fin, la vía más idónea es el ejercicio de acciones colectivas, de modo que un solo proceso judicial pueda servir para dispensar tutela a un grupo numeroso de perjudicados identificados o, incluso, a todos ellos, hayan quedado identificados o no durante el proceso - todo dependerá del sistema de litigación colectiva que exista en cada Estado.

16. Cuando la Comisión Europea lanzó la iniciativa para regular las acciones por daños en materia de competencia ésta fue una de las cuestiones nucleares que se abordaron (así se pone de manifiesto en el Libro Verde y en el Libro Blanco ${ }^{30}$ ). El tema, finalmente, se excluyó, sin duda por su carácter polémico y, posiblemente también, por el temor a la propagación del sistema de acciones colectivas "a la americana"; 31 el motivo ofrecido, sin embargo, fue la conveniencia de abordar los problemas que suscita la litigación colectiva de forma horizontal y homogénea, en vez de sectorial. Por eso, el considerando 13 de la Directiva establece lo siguiente: "La presente Directiva no debe exigir a los Estados miembros que introduzcan mecanismos de recurso colectivo para la aplicación de los artículos 101 y 102 del TFUE." Y, por eso también, en paralelo, la Recomendación sobre procesos colectivos de $2013^{32}$, aunque alude expresamente al Derecho de la competencia como uno de los ámbitos en los cuales es necesaria la existencia de procesos efectivos de recurso colectivo ${ }^{33}$, se decanta claramente por un sistema de tutela colectiva de modelo opt-in, con un control importante sobre la legitimación y la financiación de la acción colectiva, y muestra asimismo su preocupación por evitar un solapamiento entre acciones colectivas y procedimientos sancionadores (para las acciones consecutivas). ${ }^{34}$

17. La neutralidad de la Directiva en este punto determina que deban aplicarse sin más las reglas procesales de cada Estado miembro en materia de acciones colectivas, que no tienen tampoco por qué estar adaptadas a la Recomendación de $2013^{35}$-y cuya mayor o menor eficacia es, sin duda, uno de los factores clave que pueden tenerse en cuenta, en supuestos transfronterizos, a la hora de efectuar el forum shopping a que se ha hecho referencia antes-.

30 Cfr. I. Ortiz Baquero, La aplicación privada..., cit., pp. 314-321.

31 Cfr. J. López SÁnchez, El sistema de las “class actions” en los Estados Unidos de América, Comares, Granada, 2011.

32 Recomendación de la Comisión de 11 de junio de 2013 sobre los principios comunes aplicables a los mecanismos de recurso colectivo de cesación o de indemnización en los Estados miembros en caso de violación de los derechos reconocidos por el Derecho de la Unión (DO L 201 de 26 de julio de 2013, pp. 60-65).

33 Vid. el considerando 7 de la Recomendación: "Los ámbitos en que se ejerce la acción privada complementaria para hacer valer los derechos reconocidos por el Derecho de la Unión, en forma de recurso colectivo, son la protección de los consumidores, la competencia, la protección del medio ambiente, la protección de los datos personales, la normativa sobre servicios financieros y la protección de los inversores. Los principios establecidos en la presente Recomendación deben aplicarse de forma horizontal y uniforme a dichos ámbitos, pero también a cualesquiera otros en los que las demandas colectivas de cesación o de indemnización por daños y perjuicios derivados de la violación de derechos reconocidos por el Derecho de la Unión sean pertinentes."

34 Cfr. en este punto el considerando 22 de la Recomendación ["En los ámbitos del Derecho en que una autoridad pública esté facultada para adoptar una decisión que declare que se ha producido una violación del Derecho de la Unión, es importante garantizar la coherencia entre la decisión definitiva sobre dicha violación y el resultado de la acción colectiva de recurso. Además, en el caso de las acciones colectivas interpuestas como consecuencia de una decisión de una autoridad pública (acciones consecutivas), se supone que la autoridad pública, al constatar la violación del Derecho de la Unión, ya ha tenido en cuenta el interés público y la necesidad de evitar los abusos"'] y, sobre todo, los apartados 33 y 34, que 1 levan la rúbrica explícita de "Acciones colectivas consecutivas": "33. Los Estados miembros deberían asegurarse de que, en las materias legislativas en que una autoridad pública es competente para adoptar una decisión que constate una violación del Derecho de la UE, las acciones de recurso colectivo no se interpongan, por regla general, en tanto la autoridad pública no haya concluido definitivamente el procedimiento que inició con anterioridad a la acción privada. Si el procedimiento de la autoridad pública se incoara tras la interposición de la acción de recurso colectivo, el órgano jurisdiccional debería evitar dictar cualquier resolución contraria a la decisión prevista por la autoridad pública. A tal fin, el órgano jurisdiccional podrá suspender el recurso colectivo hasta la conclusión del procedimiento de la autoridad pública. 34. Los Estados miembros deberían garantizar que, en caso de acciones consecutivas, a las personas que aleguen haber sufrido daños no se les impida reclamar una indemnización por el hecho de que hayan expirado los plazos de prescripción o caducidad antes de la conclusión definitiva del procedimiento por la autoridad pública."

35 Como sucede, de hecho, en nuestro país, cuyo sistema de acciones colectivas, esbozado en los artículos 11 y concordantes de la LEC, no responde al esquema por el que ha mostrado su preferencia la Comisión en la Recomendación de 2013. 
18. En nuestro país la propuesta de ley de 2015 no contiene ninguna referencia a esta cuestión, ${ }^{36}$ de modo que será posible servirse del sistema de acciones colectivas resarcitorias establecido en los artículos 11 y concordantes de la LEC. La legitimación activa, por ello, se deducirá del propio artículo 11 LEC. ${ }^{37}$ En la mayoría de los casos, además, habrá que dar por descontado que nos hallaremos ante litigios para la tutela de intereses difusos, debido a la dificultad de determinar e individualizar en el proceso a los concretos sujetos perjudicados. Esto, en consecuencia, limita la iniciativa para el ejercicio de acciones al Ministerio Fiscal (art. 11.5 LEC) y a las asociaciones de consumidores y usuarios que, conforme a la ley, sean representativas (art. 11.3 LEC). ${ }^{38}$

19. En la práctica, la etiología de las asociaciones de consumidores hace difícil imaginar que puedan ser especialmente proactivas a la hora de promover el ejercicio de acciones de este tipo; lo mismo cabe decir del Ministerio Fiscal. Y, en todo caso, lo que sí resulta realmente difícil de imaginar es que las asociaciones o el Ministerio Fiscal se decanten por ejercer acciones de daños de forma directa (stand alone), sea previa o paralela a la existencia de un procedimiento sancionador: cabe imaginar, más bien, que se sumen al sistema de acciones consecutivas of follow-on, una vez conocido el desenlace final del procedimiento sancionador.

20. Son muchos, en todo caso, los vericuetos a que da lugar lo alambicado de la regulación de la LEC en materia de acciones colectivas resarcitorias, como, por ejemplo, la exigencia de dar publicidad previa al ejercicio de la demanda (art. 15 LEC), que puede ser muy costosa; ${ }^{39} \mathrm{o}$ los retrasos que puede provocar su posible acumulación con acciones paralelas (art. 76.2.1 ${ }^{\circ}$ LEC). A efectos prácticos, sin embargo, las mayores dificultades cabe situarlas en la cuantificación del daño y, sobre todo, en la ejecución en sí de un eventual pronunciamiento condenatorio. Nuestro ordenamiento no permite en este ámbito fórmulas flexibles, como la consistente en que la entidad demandada sea condenada al pago de una suma a tanto alzado que después podría repartirse entre los perjudicados o gestionarse por un fiduciario para promover iniciativas en favor de los perjudicados (al modo de lo que sucede en Estados Unidos). De manera diversa, en el esquema de la LEC es necesario que la sentencia establezca el importe concreto (o la prestación no dineraria) a que tendrá derecho cada uno de los individuos perjudicados (art. 221.1.1 ${ }^{\mathrm{a}}$ LEC), que será también quien deba reclamarla en vía ejecutiva: sin más, si figura nominatim en la sentencia; por la vía del expediente del artículo 519 LEC, si no es así (acreditando que concurren en él las circunstancias establecidas en la sentencia). La aplicación de estos mecanismos, sin embargo, no parece especialmente operativa en un contexto como el que nos ocupa ahora, en que las cuantías pueden ser muy reducidas, de modo que el impacto real de la condena sobre el infractor puede acabar siendo muy pequeño. ${ }^{40}$ En definitiva, mientras no se modifique el régimen legal de las acciones colectivas en nuestro

${ }^{36}$ Algo que lamenta J.I. Ruiz Peris, "Tiempos de cambio: del monopolio de la aplicación pública del derecho de la competencia a la responsabilidad compartida", en J.I. RuIz PERIs (dir.), La compensación de los daños por infracción de las normas de competencia tras la Directiva 2014/104/UE, cit., pp. 15-52, p. 26.

37 También se llegaría al artículo 11 LEC por remisión del artículo 33.1 de la Ley de Competencia Desleal (puesto en relación, a su vez, con el artículo 3 LDC). No cabe aplicar aquí, en cambio, los artículos 53 y 54 TRLGDCU, porque esta materia escapa del ámbito de aplicación de dicha norma.

38 Recuérdese que, a nivel nacional, sólo tienen la consideración de representativas a estos efectos las asociaciones que formen parte del Consejo de Consumidores y Usuarios -art. 24.3 TRLGDCU-; si el ámbito territorial del conflicto afecta fundamentalmente a una comunidad autónoma, entonces se atendrá a lo que establezca su legislación específica.

39 Así lo advierte también J. MARTíN PASTOR, "Las acciones colectivas en España: especial referencia a la aplicación privada de la competencia”, en J.I. RuIz PerIs (dir.), La compensación de los daños por infracción de las normas de competencia tras la Directiva 2014/104/UE, cit., pp. 187-229, pp. 209 y 229.

40 La experiencia inglesa da cuenta del "éxito" en 2008 de una acción colectiva, promovida por una asociación de consumidores, en reclamación de indemnización por el precio excesivo de camisetas de la selección inglesa y de un conocido equipo de fútbol, a resultas de un acuerdo de fijación de precios entre las grandes distribuidoras de estos productos (durante 2000 y 2001). La reclamación se articuló a través del mecanismo de la Group Litigation Order, que responde a los esquemas del optin. La acción desembocó en una transacción, en virtud de la cual: 1) quienes se habían unido a la demanda cobrarían 20 libras (habían pagado hasta 39.99 por cada camiseta); 2) quienes no se hubieran unido podrían cobrar 10 libras si aportaban prueba de la adquisición o la camiseta en sí, con la etiqueta intacta (ténganse en cuenta las fechas). Puede accederse a la información a través de http://news.bbc.co.uk/2/hi/business/7178958.stm (noticia fechada el 9 de enero de 2008). 
ordenamiento, no cabe esperar un ejercicio masivo -ni siquiera "moderado"- de acciones colectivas en beneficio de los consumidores perjudicados por prácticas colusorias o abusos de posición dominante. ${ }^{41}$

\section{La acumulación de pretensiones por parte de empresarios perjudicados y la transmisión one- rosa del crédito indemnizatorio}

21. Cabe asumir, en vista de lo anterior, que el grueso de la litigación en este ámbito, incluso cuando se transponga la Directiva, seguirá concentrado en los empresarios perjudicados que tengan la consideración de adquirentes directos o indirectos de los bienes y servicios afectados por el cártel o el abuso de posición dominante. ${ }^{42} \mathrm{Y}$ podrá tratarse tanto de demandas del tipo independiente (stand alone), como de pretensiones consecutivas (follow on) -al menos en principio, porque la Directiva muestra una preferencia implícita por esta segunda modalidad-.

22. La experiencia práctica pone de manifiesto que, con frecuencia, este tipo de pretensiones las pueden ejercitar de forma conjunta varios perjudicados: seguirán así siendo frecuentes, primordialmente por razones de economía procesal, los casos de acumulación de acciones. Nada se dice al respecto en la Directiva ni en la propuesta de ley de 2015, pero tampoco parece necesario. Al menos desde un punto de vista normativo, la acumulación de acciones no debería suscitar problemas, pues la exigencia del artículo 72 LEC de conexión por razón del título o causa de pedir se cumple cuando todos los demandantes afirman haberse visto perjudicados por el mismo cártel o el mismo abuso de posición dominante.

23. Más ardua puede ser la situación que se produzca cuando se tramiten de forma separada acciones de daños derivadas del mismo ilícito competencial, promovidas por distintos actores o grupos de actores, especialmente si se tiene en cuenta que los demandados no siempre tienen por qué coincidir (dada la solidaridad en la responsabilidad de los protagonistas de un cártel). En principio, nuestro sistema en este punto se decanta por la acumulación de procesos: el artículo 76 LEC da cabida sin problemas a estos casos, cuando se trata de procesos cuya tramitación separada podría dar lugar a sentencias con pronunciamientos contradictorios, incompatibles o mutuamente excluyentes: y esto es lo que sucederá, sin duda, cuando en todos ellos se discuta acerca de la calificación de la conducta de los demandados o sobre la cuota de responsabilidad de cada uno de los implicados en el cártel. Semejante situación, en la práctica, se puede plantear básicamente cuando las acciones separadas se ejercitan antes de que exista resolución firme en el ámbito sancionador. Pero cuando no suceda la anterior (en especial, cuando se trate de reclamaciones consecutivas frente a sujetos pasivos no coincidentes), no siempre será sencillo establecer la procedencia de la acumulación de procesos, lo cual puede ser problemático de cara a dar cumplimiento a lo dispuesto en el artículo 15.2 de la Directiva (y en la propuesta de nuevo artículo 80 LDC), que expresamente abogan por una coordinación para "evitar que las acciones por daños ejercitadas por demandantes de distintos niveles de la cadena de suministro aboquen a una responsabilidad múltiple o a la ausencia de responsabilidad del infractor". ${ }^{43}$

24. Junto a esto, la lectura de la Directiva abre la puerta a una opción que, al menos en nuestro ordenamiento, puede considerarse algo extraña: la existencia de entidades especializadas en reclamar daños derivados de ilícitos competenciales sobre la base de la previa adquisición por su parte de esos créditos indemnizatorios de empresas perjudicadas. Un ejemplo de esta situación se pone de manifiesto,

${ }^{41}$ Cfr. también E. Olmedo Peralta, "La reclamación de daños...”, cit., passim. Según J. Martín Pastor, sólo se ha podido identificar hasta la fecha un caso de acción colectiva en este ámbito, que acabó además siendo sobreseído por falta de legitimación de la entidad demandante ("Las acciones colectivas...", cit., p. 228).

${ }^{42}$ La Directiva, de hecho, abre la puerta al ejercicio de acciones tanto de compradores directos como indirectos (cfr., ante todo, las definiciones del artículo 2, apartados 23 y 24). Se trata, no obstante, de una opción discutible, ante las dificultades prácticas que genera la necesidad de tomar en consideración la posición jurídica de sujetos que se hallan en situaciones potencialmente muy diferentes (cfr. las críticas al respecto de H. Brokelmann, "La Directiva de daños...", cit., pp. 15 y 23; también de J. Alfaro Águila-Real, “Contra la armonización positiva”, cit., p. 5).

${ }^{43}$ Cfr. infra, V.2. 
una vez más, en la STJUE recaída en el asunto CDC Hydrogen Peroxide, en el que la demandante, Cartel Damage Claims, es precisamente una sociedad belga que tiene por objeto reclamar por vía judicial y extrajudicial el pago de los créditos indemnizatorios de empresas afectadas por un cártel. ${ }^{44}$

25. Desde posiciones muy restrictivas cabría plantearse hasta qué punto resulta o no posible, al menos en nuestro ordenamiento, la transmisión onerosa de créditos indemnizatorios de este tipo. A mi juicio, la amplitud de los términos en que se expresan los artículos 1112 («todos los derechos adquiridos en virtud de una obligación son transmisibles») y 1526 CC («cesión de un crédito, derecho o acción») permiten sostener sin dificultades la viabilidad de esta fórmula. Lo que resultaría en su caso mucho más discutible es que la Directiva, como tal, pudiera abordar la regulación directa de la transmisibilidad de este tipo de créditos de forma general, por falta de competencia normativa; no obstante, lo que sí se hace en ella es asumirla como existente y como aceptable, al menos en dos ocasiones. Se hace, en primer término, en el artículo 2.4), en sede de definiciones, respecto de lo que ha de entenderse por acción por daños: "toda acción conforme al Derecho nacional, mediante la cual una parte presuntamente perjudicada, o una persona en representación de una o varias partes presuntamente perjudicadas cuando el Derecho de la Unión o nacional prevean esta facultad, o una persona física o jurídica que se haya subrogado en los derechos de la parte presuntamente perjudicada, incluida la persona que haya adquirido la acción, presente ante un órgano jurisdiccional nacional una reclamación tendente al resarcimiento de daños y perjuicios". Y vuelve a reconocerse la existencia de esta vía de adquisición de la condición de legitimado activo en el artículo 7.3, al hacer referencia a los límites impuestos al uso de las pruebas: "Los Estados miembros velarán por que las pruebas que sean obtenidas por una persona física o jurídica exclusivamente mediante el acceso al expediente de una autoridad de la competencia y que no estén contempladas en los apartados 1 o 2 solo puedan ser utilizadas en una acción por daños por dicha persona o por la persona física o jurídica que sea sucesora de sus derechos, incluida la persona que haya adquirido su reclamación." Estas previsiones se han incorporado sin mayores dificultades a la propuesta de 2015: la primera, como definición, en la propia propuesta de ley; la segunda, como propuesta de un nuevo artículo 283 quater d) 3 LEC. Cabe esperar así que, aunque sea por esta vía indirecta, la trasposición de la Directiva ofrezca un mayor grado de certeza o seguridad jurídica a esta posibilidad, que en la praxis de otros Estados miembros se está revelando como muy eficaz para activar la aplicación privada del Derecho de la competencia. ${ }^{45}$

\section{Problemas en relación con la determinación de los hechos y con la prueba}

26. Los litigios para el ejercicio de acciones de daños son por definición litigios complejos. Y lo son, en gran medida, por las dificultades que puede entrañar la determinación de los hechos relevantes para establecer la responsabilidad de los demandados y el daño experimentado por los demandantes (especialmente, su importe). Uno de los propósitos de la Directiva es precisamente ofrecer soluciones a estas dificultades, como forma de evitar que se conviertan, en la práctica, en barreras que impidan el éxito de reclamaciones justas y minen el principio de efectividad de las normas sobre defensa de la competencia ${ }^{46}$ La Directiva aborda estos problemas a través de herramientas diferentes. De un lado, a través de medidas que, de algún modo, tratan de facilitar la fijación como ciertos de determinados hechos relevantes para la estimación de la demanda. De otro, procurando mejorar el acceso a fuentes de prueba necesarias para sostener la pretensión y que se hallen en poder de la parte contraria o de terceros.

44 Puede verse la información que la propia entidad hace pública a través de su página web: http://www.carteldamageclaims.com/

45 Así lo apuntaba J. Alfaro Águila-Real, "Contra la armonización positiva", cit., p. 8, que señalaba que "es un buen ejemplo de cómo resolver el problema de la legitimación activa sin necesidad de acciones colectivas".

46 Cfr. R. Vallina / J.A. SAntana / A. Sellés, "Cuantificación del daño y sobrecostes en la Directiva de daños por infracciones de la competencia”, en M.A. Recuerda Girela (coord.), Problemas prácticos y actualidad del Derecho de la competencia, cit., pp. 277-296. 


\section{Facilitaciones probatorias}

27. Son varias las herramientas a través de las cuales, de algún modo, la Directiva aspira a aliviar las cargas probatorias que pesan sobre los demandantes en las acciones de daños; ${ }^{47}$ más en concreto, en relación con aquellas que pueden proyectarse sobre la existencia en sí misma de la infracción y la responsabilidad de los demandados y/o sobre la cuantificación de los daños y el correlativo importe de las indemnizaciones.

\section{A) Presunciones legales}

28. La primera de las vías para hacer operativas estas facilitaciones probatorias es el establecimiento de presunciones, que dispensan de la prueba de algunos extremos o que desplazan la carga probatoria hacia elementos indiciarios de más fácil acreditación para el demandante. La Directiva ofrece, al menos, dos buenos ejemplos.

29. El primero lo establece el artículo 17.2, en virtud del cual "Se presumirá que las infracciones de cárteles causan daños y perjuicios. Al infractor le asistirá el derecho a rebatir esa presunción." "48 Es evidente que la norma no exime al actor de la carga de acreditar su daño propio y de cuantificarlo ${ }^{49}$, pero al menos sí le exonera de aportar prueba respecto del carácter dañoso del cártel, a pesar de que, desde un punto de vista económico, puede ser una asunción cuestionable, lo que justifica, a su vez, el carácter relativo de la presunción.

30. El segundo ejemplo se encuentra en el artículo 14. El apartado 1, conforme a criterios ordinarios, arroja sobre el demandante la carga de probar la existencia y la cuantía del sobrecoste que se le ha repercutido. Sin embargo, el apartado 2 le ayuda a levantar esa carga estableciendo una presunción favorable al comprador indirecto de que se le ha repercutido el sobrecoste, lo que es tanto como establecer una presunción de daño, debido a la identificación -al menos en lo sustancial- entre daño y sobrecoste..$^{50}$

\section{B) La prueba de la cuantía de los daños}

31. Pero no sólo con presunciones se trata de aliviar las dificultades probatorias. En relación con el problema singular de la cuantificación de los daños y perjuicios, nos encontramos con dos disposiciones singulares en la Directiva. ${ }^{51}$

\section{a) La estimación del importe de los daños}

32. De un lado, se efectúa una rebaja del estándar probatorio a través de la fórmula consistente en permitir que los tribunales operen con "estimaciones". En concreto, el artículo 17.1 de la Directiva, seguido por la propuesta de nuevo artículo 76.2 LDC, establece lo siguiente: "Si se acreditara que el demandante sufrió daños y perjuicios pero resultara prácticamente imposible o excesivamente difícil cuantificarlos con precisión en base a las pruebas disponibles, los tribunales estarán facultados para estimar el

47 En opinión de D. OrdóñEz Solís, "se establece un principio de facilidad en la cuantificación de los daños que favorece al demandante", que conduce a una "dulcificación de la carga de la prueba" ("La Directiva 2014/104/UE...", cit., ep. III.4).

48 Esta presunción habría de incorporarse a nuestro ordenamiento, según la propuesta de 2015, a través de un nuevo artículo 76.3 LDC.

49 Así lo señala, para que no haya dudas, el considerando 47 de la Directiva: "Esta presunción no debe abarcar el importe preciso del daño".

50 Sería el nuevo artículo 79.2 LDC el encargo de transponer esta presunción, según la propuesta de 2015. Téngase en cuenta, no obstante, la crítica de H. BRoKelmann a la suficiencia de los indicios establecidos en la Directiva para establecer semejante presunción ("La Directiva de daños...", cit., p. 16).

${ }^{51} \mathrm{Al}$ margen de la Directiva deben tenerse en cuenta la Comunicación de la Comisión sobre la cuantificación del perjuicio en las demandas por daños y perjuicios por incumplimiento de los artículos 101 o 102 del Tratado de Funcionamiento de la Unión Europea (DO C 167 de 13 de junio de 2013) y la Guía práctica que la acompaña. 
importe de la reclamación de los daños". Aunque de forma un poco discreta, el término "estimar" tiene un significado singular, apto para ofrecer salida a dos callejones que, de otro modo, tal vez no la tendrían.

33. De entrada, permitir que el tribunal haga una estimación supone modular el estándar probatorio en relación con el quantum, asumiendo que no tiene sentido exigir plena convicción al tribunal también respecto de la cantidad exacta en que debe cifrarse el perjuicio sufrido por el demandante, dadas las múltiples variables que lo integran y lo difícil que resulta medirlas. ${ }^{52} \mathrm{Si}$ se admite la estimación, se permite que el tribunal condene al pago de una cantidad sin estar plenamente convencido (estándar probatorio ordinario) de que ésa es la realmente debida, por ser ésos realmente los daños soportados. Se trata, en cierto modo, de una norma que se encuentra a medio camino entre lo procesal (pues da pautas al juez en relación con el modo en que debe llegar a su decisión) y lo sustantivo (configurando, en alguna medida, el derecho a verse indemnizado por el daño estimado, aunque no sea el realmente soportado). ${ }^{53}$

34. El otro impasse que puede solventarse con el precepto se asocia con la dificultad de dar cumplimiento al artículo 219 LEC, que establece el deber de cuantificar y expresar con precisión en la demanda la cantidad reclamada o de fijar, al menos, unas bases de cuantificación que consistan en simples operaciones aritméticas, cuya aplicación no precise efectuar valoraciones fácticas y/o jurídicas que requieran contradicción. ${ }^{54}$ En relación con este punto, cabe hacer dos lecturas del precepto: puede pensarse que la facultad de efectuar la estimación está reservada al tribunal, quien podrá hacer uso de ella en el momento de dictar sentencia, tras valorar las pruebas practicadas, pero sin exonerar al actor de la carga de expresar y de justificar la cuantía reclamada; pero podría considerarse, igualmente, que confiere al demandante la facultad de señalar que la cantidad que reclama no es, en rigor, sino una estimación (lo que, al menos, le libera de la carga de la justificación detallada del quantum expresado). Aunque la distinción entre ambas opciones es difícil -incluso tiene algo de sofisma-, es importante a efectos de costas, puesto que los demandantes sólo podrán verse resarcidos en caso de vencimiento total (o sustancial, según doctrina jurisprudencial), y el mayor o menor grado de desviación entre lo pedido en la demanda y lo "estimado" en la sentencia cobra gran relevancia.

\section{b) El asesoramiento de las autoridades nacionales de competencia}

35. En relación con lo anterior, debe mencionarse también el artículo 17.3 de la Directiva -inspirado en lo que, a nivel europeo, dispone el artículo 15 del Reglamento $1 / 2003^{55}$ - y que se expresa en los siguientes términos:

52 Cfr. G. Siotis / E. CAÑIZARES, "El estándar de prueba en las acciones de reclamación de daños”, 1989-2007. Una reflexión sobre la política de defensa de la competencia - Libro marrón del Círculo de Empresarios, Madrid, 2008, pp. 363-398, esp. p. 372, compartiendo la apreciación de que "un estándar de prueba excesivamente exigente puede suponer un obstáculo para las reclamaciones"; en sentido similar, S. OROMí VALL-LloberA, "El ejercicio de acciones...", cit., p. 106. Sobre la metodología de cuantificación aplicada por nuestros tribunales, cfr. C. RoY PÉREz, "La cuantificación de los daños por infracción de las normas de defensa de la competencia: la experiencia judicial en España”, en A. Font i RiBAS / B. VILÀ Costa (dirs.), La indemnización por infracción de normas comunitarias de la competencia, cit., pp. 224-258; I. ORTIZ BAQUero, La aplicación privada..., cit., pp. 261 y ss.; C. Herrero SuÁrez, "La transposición de la directiva...", cit., p. 175.

53 Cfr. G. Siotis / E. CAÑIZARES, “El estándar de prueba...”, cit., p. 366, señalando cómo "el cálculo de indemnizaciones es un ejercicio complejo que requiere reconstruir la realidad bajo un escenario hipotético e inobservable en el que no existe el hecho o suceso que ocasiona el daño (en este caso, una práctica anticompetitiva). El resultado de este cálculo es necesariamente una estimación basada en supuestos que por lo general implican una simplificación de la realidad" (énfasis añadido); en el mismo sentido, cfr. también p. 374. Por eso mismo, J.I. RuIz PerIS insiste en la conveniencia de que la estimación esté sujeta en todo caso a exigencias de equidad ("Tiempos de cambio...", cit., p. 48).

54 Sobre las dificultades que plantea este precepto en un plano general, cfr. I. DíEZ-PICAZo GimÉnEz, "Reflexiones sobre el nuevo régimen de la condena genérica contenido en el artículo 219 de la Ley de Enjuiciamiento Civil", en A. CABANILLAS SÁnchez et al. (dirs.), Estudios jurídicos en homenaje al Profesor Luis Díez-Picazo, Civitas, Madrid, 2002, Tomo IV, pp. 62076230; en este ámbito más específico, cfr. también del mismo autor "Sobre algunas dificultades...", cit., p. 73; igualmente R. Vallina / J.A. SAntana / A. Sellés, "Cuantificación del daño...", cit., pp. 294-295.

55 Reglamento 1/2003, del Consejo, de 16 de diciembre de 2002 relativo a la aplicación de las normas sobre competencia previstas en los artículos 81 y 82 del Tratado (DO L 1, de 4 de enero de 2003). 
«Los Estados miembros velarán por que, en los procedimientos relativos a reclamaciones de daños y perjuicios, una autoridad nacional de la competencia pueda ofrecer, previa petición de un órgano jurisdiccional nacional, asesoramiento a este en el tema de la determinación de la cuantía de los daños y perjuicios, si dicha autoridad nacional de la competencia considera adecuado tal asesoramiento.»

Esta norma, a su vez, habría de trasponerse, con arreglo a la propuesta de 2015, con un nuevo artículo 76.4 LDC, en los siguientes términos:

«En los procedimientos relativos a las reclamaciones de daños y perjuicios por infracciones del derecho de la competencia, las autoridades nacionales de defensa de la competencia podrán informar sobre los criterios para la cuantificación de las indemnizaciones que los autores de las conductas previstas en los artículos 1,2 y 3 de la presente ley deban satisfacer a los denunciantes y a terceros que hubiesen resultado perjudicados como consecuencia de aquéllas, cuando le sea requerido por el tribunal competente».

36. Como puede apreciarse, el "asesoramiento" a que se refiere la Directiva se convierte, al cruzar el umbral del Derecho español, en "informar sobre criterios para la cuantificación" -en consonancia con lo dispuesto en el artículo 5.2 b) de la Ley 3/2013, de 4 de junio, de creación de la Comisión Nacional de los Mercados y la Competencia ${ }^{56}$, lo cual no deja de ser una restricción al abanico de posibilidades que podrían abrirse con la dicción más amplia de aquélla. Tampoco está claro el alcance ni el propósito del asesoramiento o de la información contemplados: ¿puede la información suministrada tomarse como elemento sobre el que fundar válidamente la decisión del tribunal respecto del quantum? De ser así, habría que hablar de prueba, cuyo objeto podrían ser elementos fácticos relevantes en el concreto proceso o, al menos, máximas de experiencia de aplicación a los hechos controvertidos. Esto convertiría a las autoridades nacionales de competencia en peritos, ${ }^{57}$ a todos los efectos, en la medida en que suministran al tribunal conocimientos técnicos, de los que éste carece, al efecto de poder fundar su decisión -a esto se acerca, sin duda, la función "consultiva" a que se refiere el artículo 5.2 b) de la Ley 3/2013-. Es evidente que en este tipo de procesos se asistirá a auténticas "batallas periciales" y con esta norma parece que podría abrirse la puerta a la intervención de la autoridad nacional de la competencia como "perito dirimente" o, en todo caso, como "tercer perito". Podría pensarse que una norma de este tipo, en nuestro ordenamiento, en realidad habría de tener un alcance limitado, consistente simplemente en permitir que el tribunal, a quien alguna de las partes -o las dos- le hubiera pedido la designación de perito en virtud del artículo 339.2 LEC, delegara dicho encargo en la autoridad nacional de competencia. Pero no parece que sea esto lo dispuesto, de un lado por lo limitado de la función atribuida a la autoridad; y de otro, y sobre todo, porque parece contemplarse en ella la facultad del tribunal de acordar de oficio la intervención auxiliar de la autoridad. Se trata, en nuestro ordenamiento, de una clara excepción a la regla general, contraria a las pruebas de oficio, que puede distorsionar el equilibrio entre las posiciones procesales de las partes y puede acabar teniendo incidencia sobre el reparto de las cargas probatorias. Pero, en la lógica de la Directiva, semejante potestad se halla al servicio de una correcta determinación o estimación del quantum indemnizatorio, que evite que una aplicación estricta de las reglas sobre carga de la prueba pudiera conducir a la desestimación de pretensiones con fundamento legítimo: se trata, pues, de un poder de oficio al servicio del principio europeo de máxima efectividad en la aplicación de la normativa prohibitiva de conductas anticompetitivas.

56 El precepto atribuye a la CNMC funciones como órgano consultivo, entre las que se incluye la de "Informar sobre los criterios para la cuantificación de las indemnizaciones que los autores de las conductas previstas en los artículos 1,2 y 3 de la Ley 15/2007, de 3 de julio, deban satisfacer a los denunciantes y a terceros que hubiesen resultado perjudicados como consecuencia de aquéllas, cuando le sea requerido por el órgano judicial competente."

${ }^{57}$ L. CABAllol Angelats señala expresamente cómo "[1] a posibilidad de que por parte del órgano jurisdiccional se requiera a la autoridad de la competencia para que realice observaciones tiene una cierta similitud con la realización de una pericia institucional” (“Aspectos procesales de la reclamación...", cit., p. 25); en términos similares, I. SANChO Gargallo habla de "analogía con la prueba pericial, en cuanto que auxilia al Juez con conocimientos técnicos y valoraciones", aunque rechaza la equiparación total por la posibilidad de que se acuerde de oficio por el juez (aunque, en rigor, esta posibilidad no es relevante a la hora de calificar la función del interviniente) (“Ejercicio privado...", cit., p. 29). 


\section{C) La determinación de la ilicitud de la conducta en acciones consecutivas}

37. Una manifestación adicional de la voluntad de la Directiva de facilitar la prueba en estos procesos se produce para el caso especial de las acciones consecutivas (follow-on), a través de la atribución de una eficacia vinculante singular a las resoluciones administrativas o judiciales dictadas en los procesos sancionadores impulsados por las autoridades de competencia. El artículo 9 de la Directiva y la propuesta de nuevo artículo 75 LDC abordan esta cuestión, que resulta crucial para este tipo de procesos y que puede analizarse desde un doble ángulo: el de la relación entre procesos, de un lado; y el de la determinación de los hechos, por otro. La Directiva obliga a distinguir en función de si el procedimiento administrativo y el proceso judicial están o han estado o no en manos de órganos del mismo Estado.

38. En supuestos estrictamente internos el artículo 9.1 de la Directiva exige que la constatación de que se ha producido una infracción del Derecho de la competencia, hecha en una resolución firme de una autoridad nacional de la competencia o de un órgano jurisdiccional competente, se considere irrefutable a los efectos de una acción por daños ejercitada con posterioridad ante un órgano jurisdiccional nacional. ${ }^{58}$

39. En supuestos transfronterizos, el artículo 9.2 de la Directiva obliga a los Estados a garantizar que dichas resoluciones judiciales firmes podrán ser presentadas ante los tribunales de otros Estados al menos como principio de prueba de la existencia de una infracción del Derecho de la competencia y, en su caso, que podrán valorarse junto con otras pruebas presentadas por las partes. La propuesta de 2015, sin embargo, ha optado por un criterio de máxima eficacia, equivalente al atribuido a las resoluciones internas. ${ }^{59}$

40. Al margen de otros aspectos que se tratarán más adelante, ${ }^{60}$ desde el punto de vista probatorio, está claro que la existencia de una resolución firme de una autoridad nacional de competencia o de un órgano judicial que haya intervenido después en vía de recurso libera al actor de la carga probatoria respecto de aquello que, sin duda, puede resultarle más difícil de acreditar, por la lejanía o la dificultad de acceso a las fuentes de prueba: la existencia de infracción que opera como título de base para la imputación de responsabilidad al demandado. El coste de verse liberado de esta carga, sin embargo, es también claro: es necesario esperar a la conclusión en firme del procedimiento administrativo, en su caso a través del agotamiento de la vía judicial. El legislador europeo, con ello, transmite un mensaje claro: parece preferible un ejercicio consecutivo de las acciones de daños, para evitar solapamientos y contradicciones; esta preferencia, de hecho, se refuerza con la regulación sobre prescripción y sobre interrupción de la prescripción. ${ }^{61}$

\section{Acceso a fuentes de prueba en poder del contrario y de terceros}

41. Además de facilitar la prueba respecto de los hechos constitutivos de la pretensión de resarcimiento a través de los medios ya descritos, la Directiva opta decididamente por dar un paso mucho más drástico, obligando a los Estados miembros a arbitrar mecanismos que permitan con eficacia acceder a

58 Esta norma, según la propuesta de 2015, habría de incorporarse a nuestro ordenamiento a través de un nuevo artículo 75.1 LDC, del siguiente tenor: "La constatación de una infracción del Derecho de la competencia hecha en una resolución firme de una autoridad nacional de la competencia o de un órgano jurisdiccional competente se considerará irrefutable a los efectos de una acción por daños ejercitada ante un órgano jurisdiccional español de conformidad con los artículos 101 o 102 del Tratado de Funcionamiento de la Unión Europea o el Derecho nacional de la competencia."

59 Según la propuesta, la regla habría de incluirse en un nuevo artículo 75.2 LDC, en virtual del cual "En aquellos casos en los que, debido al ejercicio de las acciones de daños por infracción de las normas de la competencia se reclamen daños y perjuicios, el tribunal estará vinculado al pronunciamiento declarativo de la infracción hecho en una resolución firme de la autoridad nacional de la competencia de cualquier Estado miembro o de un órgano jurisdiccional competente."

${ }^{60}$ Cfr. infra, V.1.

61 En concreto, la propuesta de 2015 daría cumplimiento a la Directiva a través de un nuevo artículo 74.3 LDC, en los términos siguientes: "El plazo se interrumpirá si una autoridad de competencia inicia una investigación o un procedimiento sancionador en relación con una infracción del Derecho de la competencia relacionados con la acción de daños. La interrupción terminará un año después de que la resolución adoptada por la autoridad de competencia sea firme o se dé por concluido el procedimiento de cualquier otra forma." 
fuentes de prueba que se hallen en poder de la parte contraria y/o de terceros: éste parece ser, al menos a primera vista, el "espaldarazo" de la Directiva al ejercicio de acciones autónomas o stand alone, la verdadera piedra de toque para un genuino sistema de aplicación privada de las normas sobre defensa de la competencia. No tiene sentido pensar que ninguna empresa -0 , menos aún, una asociación de consumidores- vaya a emprender el ejercicio de acciones por daños sin contar con pruebas suficientes no sólo del perjuicio padecido, sino también de la existencia de una conducta anticompetitiva por parte de la empresa o las empresas a las que se propone demandar. Y, sin embargo, son pruebas de obtención prácticamente imposible sin la cooperación del adversario o de terceros. Ocurre, además, que en muchos ordenamientos de corte continental el acceso a esas fuentes de prueba es limitado: en ocasiones, por las propias reglas procesales en sí mismas, que no contemplan un derecho a reclamar y un correlativo deber de exhibir fuentes de prueba, o lo hacen de manera muy timorata; en otros casos, se añade a lo anterior la prevalencia que se otorga a normas aparentemente colaterales a las procesales, como las relativas a la protección de datos, de información confidencial o de secretos comerciales, cuya preeminencia -si se exacerba- puede vaciar de contenido el derecho a la prueba. Es necesario, por ello, superar esas barreras y mejorar las vías para que los potenciales demandantes puedan acceder a las pruebas necesarias, pues de lo contrario la supuesta potenciación de la aplicación privada del Derecho antitrust acabaría siendo letra muerta.

42. Existe, además, una categoría de "tercero" muy significativa en este ámbito: la autoridad de competencia (europea o nacional), cuando haya puesto en marcha un expediente administrativo para la investigación y determinación de infracciones. Gracias a sus potestades coercitivas tendrá acceso a fuentes de prueba que los particulares no pueden conseguir por sí mismos y que, en su caso, tendrían que reclamar de las empresas a las que se proponen demandar. Es obvio, por ello, que los perjudicados por prácticas anticompetitivas tendrán un interés muy singular en poder acceder a la información que se haya procurado o que se haya generado con ocasión de un expediente administrativo en curso o ya resuelto por una autoridad de competencia. Pero también es evidente el interés de la propia autoridad de competencia en no verse obligada en cualquier momento a suministrar cualquier información o fuente de prueba a quien se presente como un potencial actor en ejercicio de una acción indemnizatoria: de un lado, para no poner en peligro su propia labor, que puede verse entorpecida por el ejercicio de acciones civiles (especialmente, cuando son del tipo stand alone); de otro, y sobre todo, para no privar de efecto a los programas de clemencia, que permiten exonerar o atemperar la responsabilidad de aquél, de entre los partícipes de un cártel, que denuncie su existencia y coopere en la obtención de datos que permitan sancionarlo. En relación con esto último, es habitual señalar que la empresa que se acoge al programa de clemencia puede ser mucho más vulnerable frente a acciones indemnizatorias de tipo consecutivo, puesto que el reconocimiento por su parte de la comisión de la infracción la convierte en objetivo más sencillo para los perjudicados, que respecto de ella no soportarían más cargas probatorias que las relativas a la cuantificación de sus daños.

43. En este contexto, la Directiva trata de ofrecer soluciones equilibradas, guiadas por dos ideas básicas: de un lado, se quiere promover un mejor acceso a las fuentes de prueba, aunque -admítase el giro coloquial- "sin pasarse", es decir, sin excesos desproporcionados, que permitan que las reglas sobre obtención de pruebas puedan usarse como base para fishing expeditions abusivas o que priven de todo contenido a otros derechos legítimos asociados a la libertad de empresa y a la actividad comercial; de otro lado, se quiere permitir el acceso a la información y las pruebas contenidas en los expedientes sancionadores elaborados por las autoridades de competencia, pero con los límites adecuados para evitar que se trabe su eficacia y, sobre todo, para preservar los programas de clemencia, en tanto que herramienta básica para la persecución de los cárteles. ${ }^{62}$

${ }^{62}$ Cfr. H. Brokelmann, “La Directiva de daños...”, cit., pp. 19-20; J.I. Ruiz Peris, “Tiempos de cambio...”, cit., p. 22. Para una crítica a esta supuesta necesidad de compensar de algún modo a los beneficiarios de los programas de clemencia en el ámbito de la responsabilidad por daños, cfr. I. Díez-PicAzo Giménez, "Sobre algunas dificultades...”, cit., pp. 70-71. De especial interés son las reflexiones del Abogado General M. SzPunar, de 21 de julio de 2016, presentadas en el asunto C-162/15 P, Evonik Degussa GmbH, en las que, a pesar de ser la Directiva posterior a los hechos objeto de enjuiciamiento, se sirve de ésta para señalar que la protección que merecen los documentos de clemencia no puede ser absoluta y generalizada. 
44. Son los artículos 5, 6, 7 y 8 de la Directiva los encargados de definir las claves de un sistema de acceso a fuentes de prueba compatible con la preservación de todos los intereses concurrentes. ${ }^{63} \mathrm{Se}$ trata de normas genuinamente procesales, destinadas a establecer unos estándares mínimos comunes en todos los Estados miembros, con aptitud suficiente para armonizar una de las parcelas más sensibles del ordenamiento judicial, la probatoria, aunque sea para un ámbito material muy específico. La transposición de la Directiva - de forma aún más pronunciada que la Directiva de 2004 en materia de propiedad intelectual e industrial- obliga a muchos Estados miembros a incorporar normas procesales inexistentes en materia de acceso a fuentes probatorias, y a darles encaje en sistemas poco proclives a alterar las cargas y las costumbres probatorias.

\section{A) La propuesta de incorporación de las reglas de la Directiva a través de la introducción generaliza- da de medidas de acceso a fuentes de prueba en el proceso civil español}

45. En lo que atañe a nuestro país, de lege lata el acceso a información y fuentes de prueba ha de articularse a través de diligencias preliminares (arts. 256 y sigs. LEC) y por medio de peticiones de exhibición de documentos en poder de la parte contraria o de terceros (arts. 328 y sigs. LEC). Por eso, a la hora de abordar la incorporación de estas reglas en nuestro ordenamiento, una primera opción habría podido ser la de seguir el mismo esquema que se utilizó en 2006 para implementar las normas equivalentes de la Directiva de 2004 sobre propiedad intelectual e industrial, ${ }^{64}$ y que habría consistido justamente en encajar las previsiones de los artículos 5 a 8 de la Directiva dentro del sistema de diligencias preliminares y de exhibición documental de la LEC. Se habría tratado, sin embargo, de un proceder insatisfactorio por varios motivos. De un lado, por el momento procesal para poner en marcha los expedientes de acceso a fuentes de prueba, que no están temporalmente limitados en la Directiva, pero que sí lo estarían si hubieran de usarse los cauces de las diligencias preliminares y de la exhibición documental. Además, porque los cauces actualmente existentes no asegurarían la audiencia previa del sujeto pasivo antes de que se ordene la puesta a disposición del contrario de las pruebas, algo que también exige la Directiva. Finalmente, porque esos cauces parecen estar pensados primordialmente para el demandante, a pesar de que la Directiva no hace distingos y menciona también al demandado como posible beneficiario de las medidas necesarias para mejorar el acceso a fuentes de prueba.

46. A todos los anteriores, que son argumentos técnicos, debe añadirse otro más, de pura política legislativa: puede resultar hasta cierto punto discriminatorio o injustificado que estos mecanismos de acceso a fuentes de prueba, que mejoran claramente el derecho a la tutela judicial efectiva, se contemplen sólo respecto de parcelas muy singulares del ordenamiento - como las acciones de daños que ahora nos ocupan o, antes que ellas, los derechos de propiedad intelectual e industrial-, caracterizadas por el hecho de haber sido objeto de armonización sustantiva por parte del legislador europeo y que, sin embargo, no puedan usarse de forma generalizada por cualquier litigante que, para preparar adecuadamente la defensa judicial de un derecho, necesite el acceso a información o fuentes de prueba en poder de su adversario o de un tercero que no está dispuesto a facilitárselas.

\footnotetext{
${ }^{63} \mathrm{Al}$ margen de lo establecido en la Directiva y en la normativa interna que la desarrolle, debe tenerse presente que pueden existir vías adicionales para tratar de acceder a la documentación en poder de las autoridades de competencia. En concreto, cuando se trata de la Comisión, no puede olvidarse el Reglamento 1049/2001, de 30 de mayo de 2001, relativo al acceso del público a los documentos del Parlamento Europeo, del Consejo y de la Comisión, al que aluden expresamente el artículo 6.2 de la Directiva y la propuesta de nuevo artículo 283 quater c) LEC. El Reglamento contiene una serie de excepciones que se han utilizado por la Comisión para justificar la negativa a suministrar información relevante de expedientes por infracciones de las normas de competencia (protección del objetivo de las actividades de investigación, de los intereses comerciales y del proceso decisorio de las instituciones). Sobre ellas se ha pronunciado la STJUE de 27 de febrero de 2014 (EnBW Energie Baden-Württemberg, AG C-365/12 P), que ha dado cobertura a la posibilidad de que la Comisión efectúe denegaciones genéricas aplicables a categorías de documentos, sin llevar a cabo un examen concreto e individualizado del contenido de los documentos objeto de la solicitud de acceso.

64 Directiva 2004/48/CE del Parlamento Europeo y del Consejo, de 29 de abril de 2004, relativa a las medidas y procedimientos destinados a garantizar el respeto de los derechos de propiedad intelectual (DO L 157 de 30 de abril de 2004). Su incorporación a nuestro ordenamiento se hizo a través de la Ley 19/2006, de 5 de junio, por la que se amplían los medios de tutela de los derechos de propiedad intelectual e industrial y se establecen normas procesales para facilitar la aplicación de diversos reglamentos comunitarios.
} 
47. Teniendo en cuenta los elementos anteriores, la propuesta de 2015 efectúa una apuesta decidida por aprovechar la transposición de la Directiva para llevar a cabo una reforma general del sistema probatorio de la LEC. En concreto, lo que se propone es la introducción generalizada en la ley de una herramienta nueva, las medidas de acceso a fuentes de prueba, que podrán ser acordadas por el tribunal antes del proceso o en cualquier fase del mismo, a instancia de cualquier parte y previa audiencia del contrario. Esta nueva herramienta vendría a sobreponerse -por "desbordamiento"- a las actuales diligencias preliminares y peticiones de exhibición documental, que habrían de quedar derogadas. Al elaborar la propuesta, en definitiva, se consideró que, una vez plenamente asentado el modelo procesal civil de la LEC, nuestro sistema de justicia civil ha alcanzado un nivel de madurez suficiente para ensanchar los cauces de acceso a la prueba, sin llegar en ningún caso a la amplitud del sistema de discovery "a la americana", gracias a los límites y controles propuestos y, sobre todo, debido al fuerte manejo y control judicial de la figura. Junto a una regulación general, aplicable a todo tipo de pretensiones, se daría cabida a dos bloques de especialidades por razón de la materia, respecto de derechos de propiedad intelectual e industrial y respecto de las acciones de daños en materia de defensa de la competencia, para dar cabida a las exigencias singulares derivadas de las respectivas directivas.

48. La propuesta de 2015 plantea, a tal fin, la introducción de una nueva Sección $1^{\mathrm{a}}$ bis dentro del Capítulo V dedicado a las disposiciones generales sobre prueba, del Título I del Libro II de la LEC. La nueva Sección llevaría la rúbrica "Del acceso a las fuentes de prueba" y se situaría entre la Sección 1 (dedicada al objeto, necesidad e iniciativa de la prueba) y la Sección 2 (sobre proposición y admisión de la prueba); tendría, a su vez, tres subsecciones: una con las reglas generales, otra con las especialidades en propiedad intelectual e industrial y una última con las relativas a las acciones de daños derivados de infracciones a las normas sobre defensa de la competencia.

49. El régimen propuesto descansa en la distinción clásica entre fuentes de prueba y medios de prueba: ${ }^{65}$ las medidas cuya introducción se propone tienen como finalidad permitir el acceso a fuentes de prueba, es decir, a personas u objetos que, en su caso, podrán ser utilizados en el proceso para convencer al juez de la certeza de hechos controvertidos a través de los medios de prueba que resulten convenientes. Permiten, pues, conocer documentos, informes, archivos electrónicos, lugares o personas con potencial para verificar en el proceso las afirmaciones fácticas en que se sostienen las pretensiones de las partes. Si el incidente de acceso a fuentes de prueba tiene éxito, será carga ya de la parte que lo instó proponer, en tiempo y forma, el medio o los medios de prueba que considere adecuados para trasladar al juzgador la fuerza de convicción que se deduzca de la fuente de prueba.

50. La propuesta de 2015 desarrolla, en lo que podrían llegar a ser los nuevos artículos 283 bis a) a 283 bis n) de la LEC, el régimen general para pedir, acordar y practicar medidas de acceso a fuentes de prueba, con una estructura que, en algunos puntos, guarda similitudes con la regulación de las medidas cautelares -en gran parte debido a que en ambas instituciones coincide el rasgo de la instrumentalidad y la accesoriedad respecto de un proceso declarativo sobre el fondo.

51. No es éste el lugar oportuno para un análisis detenido de la propuesta ${ }^{66}$ pero sí que importa dejar claras las bases del régimen general que se ofrece, pues en ellas han de encajar después las reglas especiales de obligada incorporación por mor de la Directiva. Y estas líneas generales son, de forma muy sucinta, las siguientes:

- Se trata de un sistema abierto, que permite en principio el acceso a cualesquiera fuentes de prueba en apoyo de cualquier posible pretensión o defensa. No obstante, se ofrece a título ejemplificativo un catálogo de posibles medidas (que recoge en lo sustancial el listado de diligencias preliminares actualmente contenidas en el artículo 256 LEC).

\footnotetext{
${ }^{65}$ Cfr. por todos J. Montero Aroca, La prueba en el proceso civil, $3^{\mathrm{a}}$ ed., Civitas, Madrid, 2002, pp. 108-110.

${ }^{66}$ Cfr. las consideraciones críticas de M.L. Escalada López, en C. Herrero SuÁrez, "La transposición de la directiva...", cit., pp. 161-165.
} 
- Las medidas se adoptarán sólo a instancia de parte (demandante o demandada), bajo la responsabilidad de quien las solicite (para cuyo aseguramiento puede exigirse la constitución de caución) y asumiendo asimismo este mismo sujeto los gastos que comporte su ejecución.

- Las medidas se adoptarán con sujeción a una serie de requisitos muy estrictos, establecidos con el claro propósito de impedir que puedan servir de base a investigaciones prospectivas e indiscriminadas. A tal fin, el solicitante habrá de aportar un principio de prueba de su derecho y se aplicarán criterios propios del principio de proporcionalidad (necesidad, subsidiariedad, instrumentalidad, menor onerosidad y especialidad). ${ }^{67}$ De forma especial, se establecen fuertes salvaguardas cuando esté en juego el respeto a normas de confidencialidad, que incluyen también un régimen de sanciones severas en caso de infracción.

- En el terreno de lo procedimental, se admiten las peticiones ante demandam o durante la pendencia del proceso, aunque siempre de forma contradictoria. Para reforzar su ejecución, se ha diseñado igualmente un régimen sancionador riguroso frente a las obstrucciones en que pudiera incurrir el sujeto pasivo de la medida en cuestión.

\section{B) Las reglas especiales sobre acceso a fuentes de prueba respecto de acciones de daños en materia de defensa de la competencia}

52. Las reglas anteriores describen el hábitat en que habrían de insertarse las reglas específicas sobre acceso a fuentes de prueba en materia antitrust. Habría de ser la Subsección $3^{\mathrm{a}}$, con la rúbrica "Medidas de acceso a fuentes de prueba en procesos para el ejercicio de acciones por daños derivados de infracciones del derecho de la competencia", la encargada de dar cumplimiento a los objetivos perseguidos por la Directiva en este punto.

\section{a) Sistema general}

53. En primer término, es imprescindible que se parta de la vigencia de una regla general que permita el acceso o -si se mira desde el ángulo de la contraparte- la exhibición de pruebas en poder del contrario o de tercero que sirvan para acreditar los hechos en que se sostenga una pretensión indemnizatoria o, en su caso, una defensa de repercusión del sobrecoste (passing on). Para reforzar esta idea general, se recuerda, en consonancia con la Directiva, que el interés de las empresas en evitar acciones por daños no constituirá un interés que pueda aducirse para justificar la denegación de las medidas pedidas [propuesta de nuevo artículo 283 quater b) 5 LEC].

54. La Directiva, no obstante, también exige que esta regla general vaya acompañada de salvaguardas suficientes para impedir que su introducción dé pie a la propagación en suelo europeo de técnicas de litigación propias de la tradición jurídica estadounidense (fishing expeditions al amparo de un discovery muy amplio) ${ }^{68}$ Por eso, la propuesta de 2015 , además de remitirse a las reglas generales sobre acceso a fuentes de prueba [propuesta de nuevo artículo 283 quater a) LEC], insiste en una serie de variables. Así, se exige que la petición esté motivada y se apoye en principios de prueba que acrediten una apariencia de derecho a favor del solicitante [propuesta de nuevo artículo 283 quater b) 1 LEC]. En esa misma línea, también se exige que se trate de una petición específica: referida a elementos específicos de prueba o a categorías pertinentes de pruebas, lo más limitadas y acotadas como sea posible [propuesta de nuevo artículo 283 quater b) 2 LEC]. Y, como corolario, se concreta el deber de proporcionalidad, señalándole al tribunal cuáles son en particular los elementos que ha de ponderar: a) la medida en que la reclamación o la defensa esté respaldada por hechos y pruebas disponibles que justifiquen la solicitud de exhibición de pruebas; b) el alcance y el coste de la exhibición de las pruebas, especialmente para

${ }^{67}$ Creo, por ello, que resulta aventurado sostener que se ha procedido a una "introducción acrítica" de un sistema cercano al discovery americano (cfr. C. HerRero SuÁrez, "La transposición de la directiva....", cit., p. 183).

68 También advierten esta intención en la Directiva P. CAllol / M. Yuste, "La directiva comunitaria...", cit., pp. $302-304$. Para una primera aproximación a la institución del discovery, cfr. G. ORMAZÁBAL SÁnCHEZ, La brecha procesal civil entre EEUU y Europa. Una visión panorámica de los principales puntos de divergencia, Tirant, Valencia, 2016, pp. 82 y ss. 
cualquier tercero afectado, también para evitar las búsquedas indiscriminadas de información que probablemente no llegue a ser relevante para las partes en el procedimiento; c) el hecho de que las pruebas cuya exhibición se pide incluyen información confidencial, especialmente en relación con terceros, y las disposiciones existentes para proteger dicha información confidencial [propuesta de nuevo artículo 283 quater b) 3 LEC].

55. La cuestión de la confidencialidad se aborda con apoyo en las reglas generales sobre medidas de acceso a fuentes de prueba: si el tribunal lo considera oportuno, podrá ordenar la exhibición de pruebas que contengan información confidencial, adoptando las medidas necesarias para proteger la confidencialidad [propuesta de nuevo artículo 283 quater b) 4 LEC]. Se precisa, eso sí, el deber del tribunal de dar pleno efecto a las reglas de confidencialidad de las comunicaciones entre abogado y cliente que resulten aplicables de acuerdo con el Derecho de la Unión Europea o con el Derecho español [propuesta de nuevo artículo 283 quater b) 6 LEC]: éste parece ser, pues, el único límite infranqueable en términos absolutos.

56. La propuesta de 2015, en este terreno de lo general, ha aspirado a dar un fiel reflejo de las normas de la Directiva. No obstante, ha considerado sensato ofrecer un listado de posibles datos e informaciones que pueden solicitarse y que, a modo estrictamente ejemplificativo, se concretan en los siguientes: 1) la identidad y direcciones de los presuntos infractores; 2) las conductas y prácticas que hubieran sido constitutivas de la presunta infracción; 3) la identificación y el volumen de los productos y servicios afectados; 4) la identidad y direcciones de los compradores directos e indirectos de los productos y servicios afectados; 5) los precios aplicados sucesivamente a los productos y servicios afectados, desde la primera transmisión hasta la puesta a disposición de los consumidores o usuarios finales; y 6) la identidad del grupo de afectados [propuesta de nuevo artículo 283 quater b) 1 LEC]. Este catálogo es expresivo de una realidad clara: estas reglas generales contemplan como destinatarios de las medidas a los potenciales demandados (más que a terceros) y, por ello, su uso cobra sentido, sobre todo, cuando se contempla el ejercicio de acciones resarcitorias independientes, del tipo stand alone.

\section{b) Reglas especiales en relación con las pruebas contenidas en un expediente de una autoridad nacional de competencia}

57. En cambio, cuando se trata del ejercicio de acciones consecutivas o paralelas a un procedimiento administrativo sancionador, las "presas más cotizadas" en el terreno probatorio se hallarán, sin duda, en el expediente de la autoridad nacional de competencia que haya tramitado o ante el que esté aún pendiente el procedimiento en cuestión. Al legislador europeo, en este punto, le preocupa impedir que las peticiones de acceso a fuentes de prueba en poder de las autoridades nacionales de competencia - logradas gracias a la incoación de procedimientos sancionadores- entorpezcan la aplicación pública de las normas sobre defensa de la competencia: sea en sentido literal, pues sería posible una especie de "parasitismo" constante de demandantes privados respecto de expedientes administrativos aún no concluidos; sea en sentido figurado, poniendo en peligro los programas de clemencia ${ }^{69}$ algo que sucedería si la autoridad nacional debiera facilitar sin limitaciones información respecto de la empresa que ha colaborado (surgiría para ésta el riesgo, claramente disuasorio, de verse sujeta, en vía de private enfor-

69 La necesidad de encontrar un equilibrio entre el acceso a los documentos en manos de la Comisión y la preservación de la eficacia de los programas de clemencia ya fue abordada, con prudencia, pero con resultados favorables al primero de los elementos, por el Tribunal de Justicia en la STJUE de 14 de junio de 2011, Pfleiderer, C-360/09 y en la STJUE de 6 de junio de 2013, Donau Chemie, C-536/11. Cfr. S. GómEZ Trinidad, "El sistema de clemencia y el procedimiento judicial civil por daños ante la infracción de las normas de defensa de la competencia”, en A. FonT i Ribas / B. VILÀ Costa (dirs.) La indemnización por infracción de normas comunitarias de la competencia, cit., pp. 167-224; P. Pérez Fernández, "La problemática relación entre los programas de clemencia y la aplicación privada: tratamiento de la información en la Directiva 2014/104/UE”, InDret, 2013-1; F. GonZÁlez CASTilla, "Clemencia y aplicación privada: una visión desde las autoridades de competencia", en J.I. RUIz PerIs (dir.), La compensación de los daños por infracción de las normas de competencia tras la Directiva 2014/104/UE, cit., pp. 245-259. La opción de la Directiva, como señala H. BroKELMANN, es mucho más "proteccionista" ("La Directiva de daños...", cit., p. 21). 
cement a consecuencias económicas muy gravosas, a pesar de evitar o mitigar con su colaboración las sanciones propias del public enforcement). Estos objetivos -que conforman una de las líneas más claras de la política legislativa de la Unión Europea en este ámbito- se promueven a través de una serie de reglas, establecidas en la Directiva y que la propuesta de 2015 respeta fielmente:

58. Primero. Se establece, antes que nada, una regla básica de subsidiariedad, que impide al tribunal requerir a las autoridades de la competencia la exhibición de pruebas contenidas en los expedientes de éstas, salvo que ninguna parte o ningún tercero sea capaz, en una medida razonable, de aportar dichas pruebas [propuesta de nuevo artículo 283 quater c) 10 LEC]. Y se le añade una norma específica sobre ponderación que, además de los ingredientes ordinarios, obliga a tener en cuenta de forma singular ciertos factores a la hora de valorar la proporcionalidad de la medida: a) si la solicitud ha sido formulada específicamente con arreglo a la naturaleza, el objeto o el contenido de los documentos presentados a una autoridad de la competencia o conservados en los archivos de dicha autoridad, en lugar de mediante una solicitud no específica relativa a documentos facilitados a una autoridad de la competencia; b) si la parte que solicita la exhibición lo hace en relación con una acción por daños ante un órgano jurisdiccional nacional, y c) la necesidad de preservar la eficacia de la aplicación pública del Derecho de la competencia [propuesta de nuevo artículo 283 quater c) 4 LEC]. Además, la autoridad de la competencia, aunque no sea parte, está facultada para dar su opinión acerca de la solicitud (al fin y al cabo, aunque no sea parte del proceso, sí que es destinataria de la medida y, por ende, protagonista del incidente de acceso a fuentes de prueba): de forma singular se le permite manifestar su punto de vista sobre la proporcionalidad de los requerimientos de exhibición, presentando por propia iniciativa observaciones ante el tribunal llamado a decidir sobre la admisibilidad de dicha exhibición [propuesta de nuevo artículo 283 quater c) 11 LEC]; no será, pues, requerida para ello, pero tendrá margen para hacer alegaciones antes de que el tribunal tome su decisión (lo que requiere que, de algún modo, se le notifique la existencia de la petición).

59. Segundo. Se dispone, de forma especial, que hay cierta información o pruebas que no existe el deber de exhibir en tanto no haya terminado el procedimiento ante la autoridad de competencia. Hay, por tanto, una exhibición "diferida" respecto de ciertos elementos del expediente: a) la información que fue preparada por una persona física o jurídica específicamente para un procedimiento de una autoridad de la competencia; b) la información que las autoridades de la competencia han elaborado y que ha sido enviada a las partes en el curso de su procedimiento, y c) las solicitudes de transacción que se hayan retirado [propuesta de nuevo artículo 283 quater c) 5 LEC]. Se trata, en definitiva, de impedir que la información más importante del expediente "circule" o "salga" antes de que el procedimiento haya terminado. Para asegurar el respeto a esta limitación temporal se establece una regla especial de inadmisibilidad probatoria: a pesar de su utilidad y pertinencia, el tribunal civil ante el que trataran de presentarse pruebas que se encuadren en estas categorías no las admitirá si la autoridad de la competencia no ha dado por concluido el procedimiento con la adopción de una decisión o de otro modo [propuesta de nuevo artículo 283 quater d) 2 LEC].70

60. Tercero. De manera aún más especial, se establece que hay cierta información a la que nunca se tendrá acceso por estos cauces, la relativa a programas de clemencia, cuya difusión podría disuadir a los potenciales "arrepentidos" de seguir cooperando, centrada en dos categorías: a) las declaraciones en el marco de un programa de clemencia, y b) las solicitudes de transacción [propuesta de nuevo artículo 283 quater c) 6 LEC]. Lo más que podrá hacerse por el demandante en relación con estos datos es solicitar al tribunal que acceda por sí mismo a esos documentos para corroborar que efectivamente tienen ese carácter y que, en consecuencia, la negativa de exhibición amparada en ese motivo se encuentra justificada [propuesta de nuevo artículo 283 quater c) 7 LEC]. De forma análoga a lo que sucede con la

${ }^{70}$ Si la terminación del expediente administrativo se produce durante la pendencia del proceso, el óbice a la exhibición y/o a la admisibilidad de las pruebas desaparecerá y, por tanto, podrán solicitarse (si habían sido denegadas) o volver a aportarse (si habían sido inadmitidas) -usando, cuando sea necesario, el expediente de las diligencias finales o las reglas sobre aportación de pruebas en segunda instancia-. 
información de exhibición diferida, el respeto a esta regla se refuerza a través de una regla de inadmisibilidad probatoria absoluta [propuesta de nuevo artículo 283 quater d) 1 LEC].

61. Cuarto. El acceso, por tanto, sólo resulta posible y sin límite temporal respecto de los documentos preexistentes al expediente y que consten en él [propuesta de nuevo artículo 283 quater c) 9 LEC]. Pero incluso respecto de esta información se establece una reserva adicional: las pruebas que se hayan obtenido exclusivamente mediante el acceso al expediente de una autoridad de la competencia sólo podrán ser utilizadas en una acción por daños derivados de infracciones al Derecho de la competencia por dicha persona o por la persona física o jurídica que sea sucesora de sus derechos, incluida la persona que haya adquirido su reclamación [propuesta de nuevo artículo 283 quater d) 3 LEC]. No son, por tanto, pruebas que puedan "circular" de un demandante a otro: ${ }^{.1}$ aunque no se diga expresamente, parece lógico pensar que el respeto a esta regla también se articulará a través de una norma de inadmisibilidad probatoria.

62. Quinto. Al margen de las reglas especiales de inadmisibilidad probatoria, la Directiva exige la previsión de un duro régimen de sanciones, que en la propuesta de 2015 se efectúa por remisión a las normas generales sobre acceso a fuentes de prueba [propuesta de nuevo artículo 283 quater e) LEC].

63. La lectura de estas disposiciones transmite la impresión general de que el legislador europeo aspira a evitar la tramitación de procesos judiciales paralelos a los procedimientos de aplicación pública del Derecho de la competencia: es esta voluntad la que explica los límites que se imponen para acceder al contenido de los expedientes. La preferencia legal hacia reclamaciones consecutivas es clara, aunque obligue, en la práctica, a una espera para el ejercicio de las pretensiones indemnizatorias: como se ha señalado, el ejercicio anticipado de acciones autónomas sólo tendrá verdadero sentido, en la práctica, cuando al demandante le interese obtener como medida cautelar una rápida cesación de la conducta perjudicial. ${ }^{72}$

\section{La coordinación de procesos judiciales entre sí y con procedimientos sancionadores a cargo de autoridades nacionales de competencia}

\section{Coordinación entre proceso judicial y expediente administrativo sancionador}

64. Que se quiera potenciar el private enforcement del Derecho de la competencia a través de las acciones de daños no significa, ni mucho menos, una renuncia al sistema tradicional de public enforcement. Es necesario, por tanto, ser conscientes de la necesidad de abordar de forma coherente la posible interrelación entre las herramientas al servicio de cada uno de estos sistemas. Existe, en este punto, una premisa clara: la existencia de un proceso civil en ejercicio de una acción de daños carece de incidencia sobre un procedimiento administrativo sancionador -con la salvedad, antes señalada, del deber de la autoridad de competencia de suministrar acceso a ciertos documentos e informaciones que consten en el

\footnotetext{
${ }^{71}$ Como señala agudamente P. Martorell Zulueta, "las pruebas obtenidas de una autoridad de la competencia no pueden ser objeto de comercio" ("La prueba del daño y la aplicación privada de la competencia", en J.I. RuIz Peris (dir.), La compensación de los daños por infracción de las normas de competencia tras la Directiva 2014/104/UE, cit., p. 318).

72 Como apunta I. DíEz-Picazo Giménez, "Sobre algunas dificultades...", cit., pp. 66 y 72; téngase en cuenta, no obstante, que los datos facilitados por F. MARCos RodríGuez apuntan precisamente en la dirección contraria: de los 323 casos detectados por el autor, el 94\% fueron stand alone, mientras que sólo 18 fueron follow-on; resulta llamativo, sin embargo, que la tasa de éxito de las acciones follow-on fue elevada (en un 66,7\% de los casos), mientras que respecto de las stand alone fue bastante modesta (fracaso en el 73\% de los casos) ("La aplicación privada...", cit., p. 96). J. Alfaro Águila-Real insiste, de hecho, en recordar que todo el esfuerzo normativo desarrollado por las instituciones europeas y nacionales sólo servirá para la mejora de las acciones follow-on ("Contra la armonización positiva", cit., pp. 14-17). En este sentido, cfr. también A. CASADO NAVARRo, "La directiva 2014/104/UE sobre acciones por daños en materia de competencia: una apuesta por las «follow-on actions»", en J.I. RuIz Peris (dir.), La compensación de los daños por infracción de las normas de competencia tras la Directiva 2014/104/ $U E$, cit., pp. 427-450.
} 
expediente-. Pero el proceso civil no paraliza el procedimiento administrativo, ni la eventual sentencia civil ha de tener eventuales repercusiones sobre el desenlace del procedimiento administrativo. Lo que importa, en consecuencia, es determinar cuál es el grado de incidencia que puede tener el procedimiento administrativo respecto del proceso civil. Y esa incidencia importa en la medida en que el procedimiento administrativo y el proceso civil se pueden proyectar sobre una cuestión común: la determinación de la existencia de una infracción a las normas sobre competencia, que es el objeto principal del procedimiento sancionador, pero que integra también uno de los elementos que conforman la causa de pedir de la acción civil de indemnización. Autoridades administrativas y jueces civiles, por tanto, pueden estar llamados a pronunciarse respecto de la misma cuestión, con el consiguiente riesgo de que se llegue a respuestas contradictorias en ambas sedes, un resultado que por sí mismo no es deseable y que el ordenamiento de algún modo debe evitar.

65. Hasta la aprobación de la Directiva, la única regla a nivel europeo sobre esta materia era el artículo 16.1 del Reglamento 1/2003, que impide a los tribunales nacionales, cuando se pronuncien sobre acuerdos, decisiones o prácticas anticompetitivas, adoptar resoluciones incompatibles con la que haya sido adoptada por la Comisión ${ }^{73}$ y que, como se verá seguidamente, alcanza un nivel mayor de concreción y de extensión en el artículo 9 de la Directiva. ${ }^{74}$ A nivel interno, por el momento, las únicas reglas con que contamos al respecto se proyectan sobre dos ámbitos diferentes.

66. De un lado, hay que contar con la previsión del artículo 15 bis LEC, introducido a resultas de la aprobación de la LDC de 2007, que contempla la intervención en el proceso civil como amicus curiae de la autoridad de competencia (la Comisión Europea, la CNMC o la autoridad autonómica), ${ }^{75}$ que les permitirá aportar información o presentar observaciones escritas o verbales sobre cuestiones relativas a la aplicación de las normas pertinentes de defensa de la competencia. ${ }^{76}$ De este modo, la autoridad de competencia puede tratar de influir sobre la calificación que pueda hacer el tribunal civil acerca de las conductas atribuidas al demandado o a los demandados; y puede hacerlo, de hecho, aportando pruebas de las que carezca el propio tribunal civil (por no haberlas aportado las partes). ${ }^{77}$ Lo peculiar, en este punto, es el derecho que tiene la autoridad nacional de competencia para solicitar del tribunal la remisión de los documentos necesarios para realizar su valoración: el flujo de información del tribunal hacia la autoridad administrativa parece inevitable, en contraste con las limitaciones que se habrán de imponer al flujo inverso.

67. De otro, se hallan dos preceptos, también introducidos en la LEC en 2007 en acompañamiento de la aprobación de la LDC, que permiten la suspensión del plazo para dictar sentencia en primera instancia o en apelación, cuando exista un expediente administrativo ante la Comisión Europea o ante la autoridad nacional o autonómica "y resulte necesario conocer el pronunciamiento del órgano administrativo"; cuando se acuerde esta suspensión, se notificará al órgano administrativo, que a su vez deberá dar traslado de su resolución al tribunal (cfr. arts. 434.3 y 465.6 LEC).

73 Y debe recordarse que, en este punto, el Reglamento "codificó" algo que ya había reconocido el Tribunal de Justicia en la STJUE de 28 de febrero de 1991, Delimitis, C-234/89, Rec. 1991, p. I-00935 (apartados 47 y ss.); y también en la STJUE de 14 de diciembre de 2000, Masterfoods, C-344/98, Rec. 2000, p. I-11369 (apartados 50 y ss., en la que se establece que esa prevalencia debe conducir a la suspensión del proceso judicial nacional en tanto no alcance firmeza la decisión de la Comisión que haya sido impugnada).

74 Para una adecuada comprensión de la materia resulta imprescindible A.L. Calvo Caravaca / J. Suderow, "El efecto vinculante de las resoluciones de las autoridades nacionales de competencia en la aplicación privada del Derecho antitrust", Cuadernos de Derecho Transnacional (Octubre 2015), Vol. 7, No 2, pp. 114-157.

75 Sobre el precepto, cfr. I. Hualde López, "Comentario al artículo 15 bis", en F. Cordón Moreno (dir.), Comentarios a la Ley de Enjuiciamiento Civil, $2^{\text {a }}$ ed., Aranzadi, Cizur Menor, 2011. Para hacer posible esta intervención es necesario, en todo caso, que la autoridad de competencia tenga conocimiento de la existencia del proceso o del recurso: a tal fin, el artículo 404.3 LEC ordena al secretario judicial dar traslado a la CNMC de la resolución admitiendo a trámite la demanda y el artículo 461.5 LEC ordena lo mismo respecto de la admisión a trámite del recurso de apelación.

${ }^{76}$ Habrán de hacerlo diez días antes de la celebración del juicio o dentro del plazo de oposición o interposición del recurso interpuesto.

77 Con la limitación, expresamente establecida en el precepto, de aquellas directamente asociadas a un programa de clemencia. 
68. Estos dos últimos preceptos, sin embargo, son problemáticos. De entrada, porque otorgan carácter discrecional a la decisión sobre suspensión, lo cual no resultaría plenamente coherente con una eventual voluntad de otorgar eficacia vinculante a la resolución administrativa -algo obligado, de hecho, en virtud del artículo 16 del Reglamento 1/2003, cuando se trata de decisiones de la Comisión-. ${ }^{78}$

69. También resulta criticable que retrasen el momento en que resulta posible la suspensión hasta la apertura del plazo para dictar sentencia: y es que si lo relevante para el proceso civil es llegar a saber si en vía administrativa se declaró la existencia de una infracción a las normas de competencia, sería útil que ese dato pudiera manejarse por las partes en el proceso y no sólo quedase a la apreciación del tribunal al dictar sentencia, razón por la cual sería razonable que el tribunal tuviera la potestad de ordenar la suspensión del proceso civil en un momento anterior al actualmente previsto o que, en su defecto, se permitiera la apertura de un turno especial de alegaciones antes del dictado de la sentencia, una vez se levantara la suspensión, para que las partes pudieran expresar su posición acerca del alcance vinculante que ha de darse a la resolución en cuestión.

70. Al margen de lo anterior, lo más conflictivo es determinar cuál ha de ser la eficacia que la resolución administrativa ha de tener sobre el proceso civil en suspenso: ¿puede una resolución administrativa desplegar efectos sobre un proceso judicial, al menos en lo relativo a la determinación de si se ha producido o no una infracción de las normas de defensa de la competencia? ¿Puede al menos desplegar esos efectos una sentencia dictada por un tribunal del orden contencioso-administrativo ante el que se haya impugnado la resolución administrativa que haya constatado esa infracción y haya impuesto la sanción correspondiente? ${ }^{79}$

71. Un esbozo de respuesta afirmativa podría deducirse del artículo 42.3 LEC, que establece lo siguiente: "No obstante lo dispuesto en los apartados precedentes, cuando lo establezca la ley o lo pidan las partes de común acuerdo o una de ellas con el consentimiento de la otra, el Secretario judicial suspenderá el curso de las actuaciones, antes de que hubiera sido dictada sentencia, hasta que la cuestión prejudicial sea resuelta, en sus respectivos casos, por la Administración pública competente, por el Tribunal de Cuentas o por los Tribunales del orden jurisdiccional que corresponda. En este caso, el Tribunal civil quedará vinculado a la decisión de los órganos indicados acerca de la cuestión prejudicial." El precepto, por tanto, se muestra abierto a ese tipo de vinculaciones, aunque las supedita a la previsión legal -de momento inexistente en el ámbito que nos ocupa-o al acuerdo de las partes -con el que no resulta fácil contar-. La jurisprudencia del Tribunal Supremo, como es bien sabido, se ha mostrado tendencialmente favorable a reconocer eficacia vinculante a los pronunciamientos firmes recaídos en el orden contencioso-administrativo respecto de los hechos sometidos después a debate en un proceso civil de reclamación de daños. ${ }^{80}$

72. La Directiva y su desarrollo por la propuesta de 2015 aportan una solución algo más clara. El artículo 9 de la Directiva, en consonancia con el artículo 16.1 del Reglamento 1/2003, establece que, en supuestos puramente internos, la resolución firme tendrá efectos vinculantes: la constatación de una infracción del Derecho de la competencia hecha en una resolución firme de una autoridad nacional de la competencia o de un órgano jurisdiccional competente debe considerarse irrefutable a los efectos de una

78 Cfr. A. Martínez Sánchez / J. Rodríguez Ordóñez, "La aplicación del Derecho de la competencia por el juez civil español”, cit., pp. 408-410; y, sobre todo, A.L. Calvo Caravaca / J. Suderow, “El efecto vinculante...”, cit., pp. 124-128.

79 I. SANCho Gargallo ya ofrecía una respuesta afirmativa a esta cuestión antes de la aprobación de la Directiva, en aplicación de las reglas ordinarias sobre eficacia positiva de la cosa juzgada material ("Ejercicio privado...", cit., pp. 26-27); el problema de esta tesis, a mi juicio, es que las partes de ambos procesos no son idénticas, como exige el artículo 222.4 LEC. Un claro repaso de la situación previa a la Directiva lo ofrece C. Herrero SuÁrez, "La transposición de la directiva...", cit., pp. 165-168.

${ }^{80}$ Cfr. la STS (Sala 1ª) de 7 de noviembre de 2013 (núm. 651/2013), en relación con el llamado "cártel del azúcar", que establece, sin embargo, una cláusula de salvaguarda: la divergencia podría ser posible si el tribunal civil la hubiera razonado de forma expresa; el criterio se mantuvo, ya sin reservas, en la STS (Sala $1^{\text {a }}$ ) de 9 de enero de 2015 (núm. 634/2014), en el asunto de la explotación de los derechos audiovisuales de partidos de fútbol. 
acción por daños ejercitada ante un órgano jurisdiccional nacional. ${ }^{81}$ Aunque se use un circunloquio basado en terminología extraña ("considerar que una constatación es irrefutable"), la atribución de eficacia vinculante es innegable y tiene una consecuencia clara: el tribunal civil, en su sentencia: a) debe tener por ciertos los hechos considerados como ciertos en el procedimiento sancionador y en los que se funde la constatación de la infracción; b) también debe considerar que esos hechos merecen la calificación de infracción a las normas del Derecho de la competencia; en consecuencia, en todo aquello en que la demanda de resarcimiento se funde en esos mismos hechos, habrá vinculación total. ${ }^{82}$

73. Para los supuestos transfronterizos ${ }^{83}$ la propuesta de 2015 ofrece la misma solución (en la versión del nuevo artículo 75.2 LDC) y opta, con ello, por el llamado "modelo alemán". ${ }^{84}$ De hecho, los términos son más claros: "el tribunal estará vinculado al pronunciamiento declarativo de la infracción hecho en una resolución firme de la autoridad nacional de la competencia de cualquier Estado miembro o de un órgano jurisdiccional competente". Ha de notarse, como ya se apuntó antes, que el artículo 9.2 de la Directiva no obligaba a tanto ${ }^{85}$ : se ha efectuado, pues, una clara apuesta a favor del reconocimiento mutuo y de la confianza en la actuación de las autoridades de competencia y de los tribunales de los demás Estados miembros. ${ }^{86}$

74. En cualquier caso, la exigencia de firmeza de la resolución recaída en el procedimiento administrativo resulta clave, ${ }^{87}$ pues legitima la decisión legal de imponer a un tribunal civil el criterio al que se ha llegado en un procedimiento administrativo sancionador: si hubo proceso contenciosoadministrativo, será una decisión judicial firme la que traslade sus efectos a otro proceso judicial, aunque se tramite ante un órgano de un orden jurisdiccional diferente; y si dicho procedimiento no existió, por falta de recurso, entonces la admisibilidad de la vinculación deriva del propio consentimiento de quien podría verse perjudicado por esa extensión de eficacia. ${ }^{88}$

75. La implementación de la Directiva, por tanto, ofrecerá de cara al futuro un parámetro claro: habrá vinculación para el tribunal civil que haya suspendido el proceso si hay firmeza de la resolución recaída en el expediente administrativo sancionador. No la habrá, en cambio, sin firmeza, aunque en esos casos nada impedirá al tribunal civil valorar las resoluciones administrativas o contenciosoadministrativas que aún no sean firmes para fundar su decisión acerca de la existencia o no de ilícito concurrencial: pero subsistirá, en todo caso, el riesgo de resoluciones contradictorias, siempre perjudicial para una de las partes, aunque no se pueda saber de antemano cuál. Si se quiere certidumbre, es evidente que será preferible esperar a la firmeza de la resolución que ponga fin al procedimiento admi-

\footnotetext{
${ }^{81}$ La propuesta de nuevo artículo 75 LDC reproduce de forma casi literal lo dispuesto en la Directiva.

82 El considerando 34 de la Directiva señala que "[1]os efectos de esa constatación deben abarcar únicamente, no obstante, la naturaleza de la infracción y su alcance material, personal, temporal y territorial, tal y como los hayan determinado la autoridad de la competencia o el órgano jurisdiccional competente en el ejercicio de sus funciones". Como apunta J.I. RUIz PeRIs, de ello se deduce que la vinculación alcanza tanto a cuestiones jurídicas como fácticas, pero que no puede tener alcance extensivo más allá de los extremos señalados ("Tiempos de cambio...", cit., p. 45). Con gran minuciosidad, cfr. nuevamente A.L. CALVO Caravaca / J. Suderow, "El efecto vinculante...", cit., pp. 131-136.

${ }^{83}$ Ha de advertirse, eso sí, de que ha de tratarse de resoluciones dictadas por autoridades de competencia o por tribunales de otros Estados miembros de la Unión Europea. Ni la Directiva ni la propuesta de 2015 abordan la eficacia que ha de otorgarse a las resoluciones dictadas por las autoridades o tribunales de terceros Estados, a pesar de su potencial incidencia práctica (cfr. también en este sentido J.I. Ruiz Peris, "Tiempos de cambio...”, cit., p. 44).

${ }^{84}$ Cfr. A.L. Calvo Caravaca / J. Suderow, "El efecto vinculante...”, cit., pp. 144-149.

85 Se conformaba con que los Estados miembros las reconocieran al menos como principio de prueba de la existencia de una infracción del Derecho de la competencia y, en su caso, pudiera valorarse junto con otras pruebas presentadas por las partes.

${ }^{86}$ H. Brokelmann, de hecho, se lamenta de la tibieza de la Directiva en este punto ("La Directiva de daños...", cit., p. 11). También se muestra crítica S. Oromí Vall-Llobera, "El ejercicio de acciones...", cit., p. 110.

87 En este sentido, cfr. H. Brokelmann, "La Directiva de daños...", cit., pp. 8-11; P. Callol / M. Yuste, "La directiva comunitaria...", cit., pp. 307-308; C. Herrero SuÁrez, "La transposición de la directiva...”, cit., pp. 168-169.

${ }^{88}$ Aunque parezca drástico, creo que lo mismo puede decirse en caso de que la ausencia de recurso ante la jurisdicción contencioso-administrativa obedezca a la interposición de éste fuera de plazo: se trata de una situación evitable e imputable exclusivamente a quien la padece.
} 
nistrativo: nos hallamos, de nuevo, ante una muestra de la preferencia del sistema hacia las acciones de daños consecutivas. ${ }^{89}$

76. Desde el punto de vista procedimental, esta vinculación del tribunal civil respecto de la resolución que recaiga en el procedimiento administrativo puede forzarse a través de lo dispuesto en los artículos 434.3 y $465.6 \mathrm{LEC}$, que resultan aplicables de oficio por el tribunal -o a instancia de la autoridad nacional de competencia, al amparo del artículo 15 bis LEC $^{90}$-: no puede descartarse, pues, que el juez civil opte por suspender el plazo para dictar sentencia hasta que gane firmeza la resolución que ponga término al procedimiento administrativo sancionador, para poder después atenerse a ella cuando llegue el momento (tendría, en cambio, menos sentido que levantara la suspensión antes de la firmeza).

\section{Coordinación entre procesos judiciales}

77. Resulta igualmente posible que una misma conducta infractora de las normas sobre defensa de la competencia determine la incoación de dos o más procesos judiciales, promovidos por perjudicados distintos y/o frente a responsables distintos (debido a la regla general que establece la responsabilidad solidaria de los miembros de un cártel). Tratándose de acciones consecutivas, la eficacia vinculante de la resolución firme recaída al término del procedimiento administrativo debería evitar que pudieran dictarse resoluciones contradictorias, pues debería darse una respuesta uniforme a la cuestión común (la existencia o no de ilícito concurrencial), en tanto que la existencia y extensión del daño de cada demandante dependerá de la realidad que se acredite en cada proceso.

78. El riesgo de resoluciones contradictorias existe, en cambio, si las acciones se entablan en ausencia de resolución sancionadora firme $-\mathrm{o}$, incluso, en ausencia de procedimiento administrativo sancionador-, pues pueden recaer pronunciamientos diversos sobre el carácter ilícito de la conducta que está en el origen de los daños alegados. No es esto algo que preocupe expresamente a la Directiva, que en consecuencia confía en los expedientes procesales nacionales destinados a evitar que se produzcan estos desenlaces: en nuestro ordenamiento se trataría primordialmente de la acumulación de procesos (arts. 74 y ss. LEC) y, en su defecto, de la suspensión por prejudicialidad al amparo del artículo 43 LEC.

79. Ahora bien, también es posible que la pluralidad de procesos civiles, unida a un abuso de las consecuencias procesales de la solidaridad entre infractores -que excluye el litisconsorcio pasivo necesario-, conduzca a situaciones inaceptables, por exceso o por defecto. La Directiva expresa su preocupación al respecto en su artículo 15, que lleva la rúbrica de "Acciones por daños ejercitadas por demandantes situados en distintos niveles de la cadena de suministro". El objetivo de la norma no parece ser evitar la existencia de pronunciamientos incompatibles o contradictorios en términos generales, sino que declaradamente se trata de evitar que las acciones por daños ejercitadas por demandantes de distintos niveles de la cadena de suministro aboquen a una responsabilidad múltiple o a la ausencia de responsabilidad del infractor. ${ }^{91}$ La norma, por ello, se halla en relación con el régimen de la repercusión de sobrecostes y el derecho al resarcimiento de los compradores indirectos. Y lo que se dispone es que, a la hora de evaluar si se cumple la carga de la prueba derivada de la aplicación de los preceptos sobre repercusión de sobrecostes (arts. 13 y 14 de la Directiva) ${ }^{92}$, los tribunales deben poder, a través de medios

89 Esta prevalencia, según se apuntó antes, también se recuerda en el apartado 33 de la Comunicación de la Comisión de 13 de junio de 2013 en materia de acciones colectivas.

90 Así lo apunta también Caballol Angelats, “Aspectos procesales de la reclamación...”, cit., p. 34.

91 Con claridad, cfr. C. Herrero SuÁrez, que pone sendos ejemplos de ambas situaciones: habría ausencia de responsabilidad si en el proceso entablado por el adquirente directo se considera acreditada la repercusión de sobrecostes (con la consiguiente desestimación de la demanda) y, por el contrario, se rechazara la repercusión cuando ejerciten la acción los adquirentes indirectos (v.g., consumidores); y, a la inversa, habría exceso de responsabilidad "si se reconoce la existencia de daños plenos tanto al comprador directo como al indirecto" ("La transposición de la directiva...", cit., p. 180).

92 La carga de la prueba de la repercusión del sobrecoste corresponde al demandado que la alega como defensa frente al comprador directo; pero corresponde al comprador indirecto que la alega como fundamento de su pretensión frente al infractor. 
disponibles en el marco del Derecho de la Unión o en el nacional, tomar en consideración debidamente cualquiera de los siguientes elementos:

- las acciones por daños que estén relacionadas con la misma infracción del Derecho de la competencia, pero hayan sido interpuestas por demandantes situados en otros niveles de la cadena de suministro;

- las resoluciones derivadas de dichas acciones por daños;

- la información pertinente de dominio público derivada de la aplicación pública del Derecho de la competencia.

Se trata, en definitiva, de que el tribunal civil que conoce de un proceso pueda tener conocimiento de que existen otros procesos en curso y, en su caso, de las resoluciones dictadas en ellos, así como de la información a cuya difusión obligan las propias reglas sobre public enforcement.

80. Los medios a través de los cuales el tribunal puede llegar a tener conocimiento de dichos extremos no están definidos en la Directiva, que se remite al propio ordenamiento europeo y a los derechos nacionales. Tampoco se especifican en la propuesta de ley de 2015, que ofrece una trasposición del artículo 15 de la Directiva a través de un nuevo artículo 81 LDC, que transcribe literalmente las previsiones de aquél. Una posible vía para ello serán las alegaciones de las partes o la información que remita, como amicus curiae, cualquier autoridad de competencia al amparo del artículo 15 bis LEC. En función del momento, podrán utilizarse a tal fin las vías procesales ordinarias o, en último término, la vía extraordinaria del artículo 271.2 LEC, que permite alegar en cualquier momento resoluciones judiciales o administrativas que puedan ser relevantes o decisivas. ${ }^{93}$ Además, y al menos respecto del tercero de los elementos (la información pertinente de dominio público derivada de la aplicación pública del Derecho de la competencia), resulta razonable una eventual apreciación de oficio.

81. Conocida esa información por el tribunal, podrá ya éste adoptar las medidas necesarias para evitar los peligros descritos en el artículo 15 de la Directiva. Cuando estén pendientes dos o más procesos, la mejor manera de evitar el resultado temido por la Directiva es coordinarlos o conectarlos de algún modo. En supuestos internos, cabe pensar en la acumulación de oficio de procesos conexos, aunque puede resultar difícil de activar si las partes son distintas, a pesar de que la infracción de base sea la misma (v.g., si adquirentes directos e indirectos perjudicados de un cártel demandan en procesos separados a empresas distintas de entre las que lo integraron). ${ }^{94}$ En situaciones transfronterizas, la única herramienta posible será la suspensión al amparo del artículo 30 del RB I bis, como advierte de hecho la propia Directiva (art. 15.2). En todo caso, será lícito para el tribunal tener en cuenta el desenlace de otros procesos; es más, a través de este cauce puede aflorar el conocimiento de una situación en que resulte preceptivo aplicar la regla del artículo 9 de la Directiva. De hecho, cuando no haya pendencia simultánea de procesos, bastará con tener en cuenta el resultado de procesos civiles o administrativos anteriores para dar eficacia al mandato del legislador europeo.

\section{Conclusión}

82. La litigación en reclamación de daños y perjuicios derivados de infracciones de las normas de competencia es por definición compleja, tanto en su dimensión sustantiva como en la procesal: no sólo por la tecnicidad de la materia, sino por la concurrencia de intereses contrapuestos de muy diversa índole, algunos estrictamente privados, otros tendencialmente públicos. Es absurdo pensar que puede haber soluciones fáciles para los problemas complicados; por eso, no hay más opción que recurrir a pro-

93 Según el artículo 271.3 LEC, estas resoluciones se podrán presentar incluso dentro del plazo previsto para dictar sentencia; cuando suceda lo anterior, se dará traslado a las demás partes, para que puedan alegar y pedir lo que estimen conveniente, con suspensión del plazo para dictar sentencia.

94 También críticos R. Vallina / J.A. Santana / A. Sellés, “Cuantificación del daño...”, cit., p. 289. 
puestas y esquemas cada vez más sofisticados -en la acepción más positiva del término-, como los que sin duda recogen la Directiva y la propuesta para su transposición a nuestro ordenamiento. Tal vez por eso la Directiva muestra también una clara preferencia por el ejercicio de acciones consecutivas: al fin y al cabo, aun siendo complejas, lo son menos que las acciones autónomas. Pero, por muy sofisticado que sea el régimen jurídico diseñado, es imposible que el legislador llegue a predecir en textos articulados todos los matices y sutilezas que puede requerir ofrecer la solución más justa en cada caso concreto, tanto a la hora de enjuiciar el fondo, como al dar respuesta a una cuestión procesal, de apariencia tal vez secundaria, pero que puede condicionar de hecho el curso entero del proceso (v.g., la negativa a ordenar la exhibición de información o de pruebas en poder del contrario o de una autoridad de competencia).

83. La Directiva -y la norma que finalmente articule su incorporación a nuestro ordenamientono ha aspirado a regular de forma exhaustiva todas las cuestiones que pueden suscitar las acciones de daños en materia antitrust; es llamativo -aunque tal vez explicable- el silencio en materia de demandas colectivas. En relación con la determinación de los hechos y el acceso a las fuentes de prueba, el sistema se apoya de modo singular en nociones de proporcionalidad, que exigen de los tribunales, desde el inicio, una seria toma de conocimiento de los elementos definidores de la controversia que, sin ser incompatible con el principio dispositivo, comportan una mayor implicación funcional del órgano judicial en el desarrollo del proceso (v.g., valorando principios de prueba para resolver sobre solicitudes de acceso a documentos o requiriendo la intervención de una autoridad de competencia). Lo mismo sucede respecto de la interrelación entre el proceso civil en curso y otros eventuales procesos civiles derivados de la misma conducta infractora, o con expedientes administrativos para la aplicación pública de las normas de competencia: una excesiva rigidez de planteamiento y una eventual cerrazón al contexto en que se desenvuelve el proceso civil son incompatibles con el sistema que pretende desarrollarse con la nueva normativa. Una aplicación correcta del régimen establecido obligará a muchos actores del proceso -y, de modo espacial, a los jueces- a "salir de su zona de confort" en cuanto al modo de afrontar muchas de las decisiones que necesariamente se van a plantear en la preparación o durante el desarrollo del litigio; creo que ahí radica el riesgo, pero también la oportunidad, de cara a una efectiva implantación en nuestro país del sistema de aplicación privada del Derecho de la competencia. 